\title{
Rules for Retinotectal Terminal Arborizations in the Goldfish Optic Tectum: A Whole-Mount Study
}

\author{
CLAUDIA A.O. STUERMER
}

Abteilung Physikalische Biologie, Max-Planck-Institut für Entwicklungsbiologie, D 7400 Tübingen, West Germany and Division of Biological Sciences, University of Michigan, Ann Arbor, Michigan 48109

\begin{abstract}
Retinal axons were labeled in the retina and optic nerve with horseradish peroxidase and traced in tectal whole-mounts. The typical network formed by retinal fibers in the five retinorecipient layers of tectum is illustrated in camera lucida drawings. Three size classes of terminal arbors were identified in the Stratum fibrosum et griseum superficiale (SFGS)-ca. $34 \times 52$, ca. $103 \times 150$, and ca. $158 \times 274 \mu \mathrm{m}$. Terminal arbors are flattened and occupy three sublayers of SFGS.

Passing an HRP-coated needle through the optic nerve labeled ganglion cells in retina and axons and terminal arbors in tectum. Terminal arbors of axons that originated in retinal annuli lay in distinct annular regions in SFGS, with old generations from central retina lying central to younger generations from peripheral retina. The tectal annuli were concentric with one another and agreed with the retinotopic map as it had been described before.

The youngest terminal arbors from peripheral retina were next to the path of their fascicle along the tectal periphery, connected to their fascicle by short, centrally directed extrafascicular axons. The oldest terminal arbors from central retina were caudally displaced from their rostral fascicle of entrance, at the end of long, caudally directed extrafascicular axons. Terminal arbors from intermediate retina occupied intermediate positions in the tectum. Rostrally, they arose from centrocaudally directed extrafascicular axons but caudally from axons of various orientations. Terminal arbors arising from those extrafascicular axons exhibited different orientations and shapes depending on their tectal position.

The spatial order of intratectal paths and terminal arbor sites, and the variability of terminal arbor orientation and shape, are consistent with an earlier model on shifting retinotectal terminals (Easter and Stuermer, '84).
\end{abstract}

Key words: terminal arbors, morphology, retinotopic order, variation of shape, shifting terminals

Retinal axons in the optic tectum of fish and amphibians terminate in reliable topographical order (Gaze, '58; Attardi and Sperry, '63; Jacobson and Gaze, '65; Meyer, '80), although retina and tectum continue to enlarge in geometrically different patterns (Meyer, '78; Raymond and Easter, '83).

While the goldfish retina grows in adding new cells in annuli, the tectum adds new cells only caudally in a crescent-shaped zone (Meyer, '78; Raymond and Easter, '83). In order to maintain a topographically ordered projection, the terminal arbors were hypothesized to abandon their old places and to relocate at retinotopically correct sites (Gaze et al., '74; Easter and Stuermer, '82; Frazer, '83). Strong support for this concept was recently created along with novel insights into the rules of retinal axon pathway order

Accepted May 29, 1984 .

Address reprint requests to Dr. C.A.O. Stuermer, Max-Planck Institut für Entwicklungsbiologie, Abteilung Physikalische Biol ogie, Spemannstr.35, D 7400 Tübingen, W. Germany. 
(Easter and Stuermer; '82; Rusoff, '84) which will be briefly summarized here: the axonal pathway in tectum consists of three segments-the path through fascicles in Stratum opticum (SO), the path through extrafascicular routes in Stratum fibrosum et griseum superificiale (SFGS), and the terminal arborization (Easter and Stuermer, '82, '83). The position of each is determined by different rules. The order of the fascicles reflects the appositional annular growth waves of the retina, such that the position and course of each fascicle is determined by its ages and the time it grew in (Stuermer and Easter, '82, '83, '84). The fascicles enter rostroperipherally into tectum and form two mirror-symmetrical fanlike arrays over the dorsal and ventral hemitectum. Fascicles from ventral hemiretina serve the dorsal hemitectum, those from dorsal retina the ventral hemitectum. All fascicles are tangent to one another rostrally. The fascicles deriving from early growth waves, i.e., old, central retina, are short and end rostrally; fascicles of later growth waves, i.e., from younger, more peripheral retina, are peripheral from those of earlier growth waves. They are longer and reach into caudal tectum.

The sites of the terminal arborizations are expected to be in places consistent with the retinotopic map. Therefore, the termination sites of ganglion cell axons of early generations (central retina) are predicted to reside in central tectum far away from their rostral fascicle of entrance. Those from later generations (peripheral retina) are predicted to be located in peripheral tectum (close to their fascicle of entrance; Stuermer and Easter, '83). This implies that the termination sites for most axon generations are not reached directly by their axons' fascicular path (Stuermer and Easter, '82, '83; Cook et al, '83).

The connection between the fascicle and the terminal arbor is mediated by the extrafascicular axon segment in SFGS. We proposed that the extrafascicular axons are the visible remnants of the terminal arbor left behind while it shifted (Easter and Stuermer, '82, '84).

In an earlier report we conveyed the spatial order of the fascicular path, the extrafascicular routes, and the expected terminal arbor sites in a model and reconstructed the developmental events which lead to an orderly map (Easter and Stuermer, '83, '84).

The present report tests the predictive power of the model and the ideas of shifting terminal arbors by examining the regional variation of axonal pathways and terminal arbors of horseradish-peroxidase (HRP)-labeled retinal axons in tectal whole-mounts.

In the first part of this study, the general morphology of retinotectal axons will be described, including the structure of the fiber networks in each retinorecipient layer, and the size, shape, and laminar distribution of terminal arbors.

In the second part, the spatial order of the axonal pathways and the locations and shapes of the terminal arbors of fibers of different retinal regions are described and analyzed.

Preliminary accounts have been presented in an abstract (Stuermer, '83).

\section{MATERIALS AND METHODS}

Adult goldfish (Carassius auratus), 5-8 cm standard length, were maintained in aerated aquaria at room temperature $\left(18-25^{\circ} \mathrm{C}\right)$. For all surgical procedures the fish were anesthetized in a $0.1 \%$ aqueous solution of tricaine methanesulfonate.

Axons of retinal ganglion cells were labeled with HRP (Type 6, Miles). To label many, the optic nerve was par- tially cut and crystals of HRP were applied to the stumps. To label a few, an HRP-coated needle was inserted through the nerve (Rusoff and Easter, '80). HRP was then transported both anterogradely to label the axon and terminals and retrogradely to label the cell bodies of origin. After 3 days' survival time, whole-mounts of retina and tectum were prepared. In the course of this and other studies on the regenerated retinotectal pathway 20 normal tecta and retinae were prepared. The retina was detached from the pigment epithelium, fixed in $4 \%$ glutaraldehyde in phos phate buffer for 20 minutes, reacted with diaminobenzidine (DAB) for 20 minutes (LaVail and LaVail, '74) or o' dianisidine (OD) (Coleman et al., '76), dehydrated, cleared in xylene, and coverslipped under Permount. Following intracardial perfusion with buffered saline, the tectal lobes were isolated; 25 were reacted in DAB (Fujisawa et al, '81), five in OD. Since DAB-reacted tecta revealed more details of labeled terminal arbors, particularly those in deeper layers, $\mathrm{DAB}$ was preferred over $\mathrm{OD}$. In order to flat-mount a tectal lobe, it was slit from the caudal pole almost to the rostral pole along the equator, flattened between a slide and coverslip, fixed 1-2 hours, dehydrated, cleared in xylene, and coverslipped under Permount. This procedure resulted in a shrinkage of tectal depth of $60 \%$ due to extreme dehydra tion and short fixation (J.T. Schmidt, personal communication).

Ten glutaraldehyde-fixed tecta were sectioned transversely on a cryostat and reacted for HRP with DAB according to Adams ('77) or with OD (Coleman et al., '76) to reveal the stratification of retinal axons and their interlaminar pathways.

All tecta reacted with DAB or OD contained heavily stained blood vessels which made photography difficult. Therefore, we documented fibers and terminal arbors in different layers mostly in camera lucida tracings under observation with $25 \times$ and $50 \times$, and $100 \times$ oil-immersion lenses.

\section{RESULTS \\ Layer-specific organization of retinal fiber networks}

Following application of HRP to the partially sectioned optic nerve, labeled retinal axons were visible in sections of the contralateral tectum in Stratum opticum (SO) and its superficial satellite band, S, in Stratum fibrosum et griseum superificiale (SFGS), Stratum griseum centrale (SGC), and Stratum album centrale (SAC), confirming many earlier reports (Schmidt, '79; Springer and Gaffney, '81; Meyer, '80). In the broad termination layer, SFGS, retinal afferents are stratified into sublayers. Previous reports by Landreth et al. ('75), using autoradiography, distinguished two layers: namely, $\mathrm{F}_{3}$, which comprised approximately the upper two-thirds of SFGS and $\mathrm{F}_{4}$, comprising the deeper one-third of SFGS. HRP revealed three sublayers within SFGS: two within $F_{3}$, which were therefore described as $F_{3 a}$ and $F_{3 b}$ (Stuermer and Easter, '84a), and $\mathrm{F}_{4}$.

Labeled retinal fibers in all retinorecipient layers are visible in successive focal planes in tectal whole mounts.

In whole mounts the thickness of the tectum and the depth of each retinorecipient layer was determined microscopically with a $50 \times$ lens by reading off the distances on the fine focus knob scale and these measurements are presented below.

In central tectum the depth from the pial surface to the top of the periventricular layer was approximately $150 \mu \mathrm{m}$, $30 \%$ less than the tectal width determined in tectal sections 
of similar-sized fish (see Methods). The retinorecipient layers were each identified by their occurrence at distinct levels of focal depth and by the morphological characteristics of the retinal fibers contributing to each separate layer (see below).

Retinal fibers of layer $\mathrm{S}$, as the most superficial retinal afferents, lay approximately $10 \mu \mathrm{m}$ deep to the pia. The fibers of $\mathrm{SO}$, in their typical fascicular arrangement, were focused between approximately 12 and $20 \mu \mathrm{m}$. SFGS, right underneath SO, extended approximately between 20 and $60 \mu \mathrm{m}$. It consisted of three layers of terminal arbors, all approximately equally thick. Three layers could only clearly be identified in regions of low fiber density, such as the central tectal region $P$ in Figure 1 , to be described below. In regions of high fiber density, only two layers were clearly distinguishable: the upper broader layer $F_{3}$ and the deeper narrow layer $\mathrm{F}_{4}, \mathrm{~F}_{3}$ and $\mathrm{F}_{4}$ are separated by a narrow, sparsely labeled zone (visible in Fig. 1; Stuermer and Easter, '84; Landreth et al., '75) and are therefore clearly distinguishable even in whole-mounts.

Labeled fibers of mid-SGC appeared between 90 and 100 $\mu \mathrm{m}$, separated from SFGS by a $30-\mu \mathrm{m}$-wide unlabeled zone. The deepest fibers of SAC, just above the cell bodies of Stratum periventriculare (SPV), were visible at approximately $130 \mu \mathrm{m}$, about $30 \mu \mathrm{m}$ deep to fibers in SGC.

The relative distances between the layers and the width they encompass correlates well with the retinal fiber distribution in tectal sections (Stuermer and Easter, '84a).

One tectal whole-mount of a 6-cm-long fish was selected to demonstrate the laminar distribution of labeled fibers. The typical arrangement of retinal axons and terminals within each layer is shown in Figures 1 and 2. Included are all processes which could be detected under observation with a $50 \times$ lens. The whole-mount (Fig. 1) had labeled fibers in the fascicles of SO (wavy lines), extended regions of terminal arbors (stippled zones), and regions largely bare of terminal arbors (clear areas).

Figure 2a shows fibers in layer S. They were small, approximately $0.5 \mu \mathrm{m}$ in diameter, and either grouped in small bundles or alone. The course of the bundles was very irregular and the distances between individual bundles varied considerably. Single fibers frequently left one bundle to join another, or to continue alone. Viewed under low magnification $(25 \times$ lens), bulbous structures were interspersed betweeen fibers and only under high-magnification lenses $(50 \times, 100 \times)$ visibly connected to them (indicated as dots in Fig. 2a); they may be terminal swellings. Terminal arbors comparable to those found in SFGS (see below) were not observed.

Distinctly separate from $\mathrm{S}$ are the numerous fibers in $\mathrm{SO}$, sketched in Figure 2b. They were too numerous to be drawn individually, and Figure $2 \mathrm{~b}$ serves only to indicate their

\begin{tabular}{ll}
\hline & \\
C & Caudal \\
D & Dorsal \\
N & Nasal \\
R & Rostral \\
SAC & Stratum album centrale \\
SFGS & Stratum fibrosum et griseum superficiale \\
SGC & Stratum griseum centrale \\
SM & Stratum marginale \\
SO & Stratum opticum \\
SPV & Stratum periventriculare \\
T & Temporal \\
V & Ventral
\end{tabular}

orientation. Axons in fascicles occur in three sizes: small, of no greater than $0.5-\mu \mathrm{m}$ diameter, medium, of about 1$1.5-\mu \mathrm{m}$ diameter, and large of $2.5-3 \mu \mathrm{m}$. Each fascicle contains numerous small, fewer medium, and a very few large axons. All stained less heavily than those in S, and all had spindlelike enlargements (visible in Figs. 2, 16) at intervals of $50-150 \mu \mathrm{m}$. The axons retained these spindles when they left their fascicle and coursed through SFGS. The significance of these spindles is unknown, but they serve as a convenient additional marker to follow retinal fibers through SFGS.

All along each fascicle, labeled fibers were seen to depart, to dip into SFGS, and to course in a different direction. (The portion of the axon from its point of exit from the fascicle to the beginning of the terminal arbor was defined as the extrafascicular axon [Easter and Stuermer, '84].) As a consequence, all fascicles contain progressively fewer fibers as they approach the equator, the boundary between ventral and dorsal hemitecta. Figure 3 exemplifies this general mode of fiber exit by showing the departing fibers of a very old fascicle in the rostral tectum. This fascicle was chosen since several of its departing axons could be traced throughout their extrafascicular course through SFGS to their terminal arborization close to the tectal center. The beginning of the fascicle is above, its end at the tectal equator below. To the right are the stem segments of the extrafascicular axons which coursed generally caudally, toward the right in this picture, and in a focal plane deep to SO.

The exiting fiber descended into one of three levels within SFGS: $F_{3 a}, F_{3 b}$, and $F_{4}$. These interlaminar fiber pathways were also observed in tectal sections. Once in their layer, they coursed over long distances, frequently several hundred micrometers, to terminate in an arbor. Those exiting from the rostral fascicle in Figure 3 deployed their

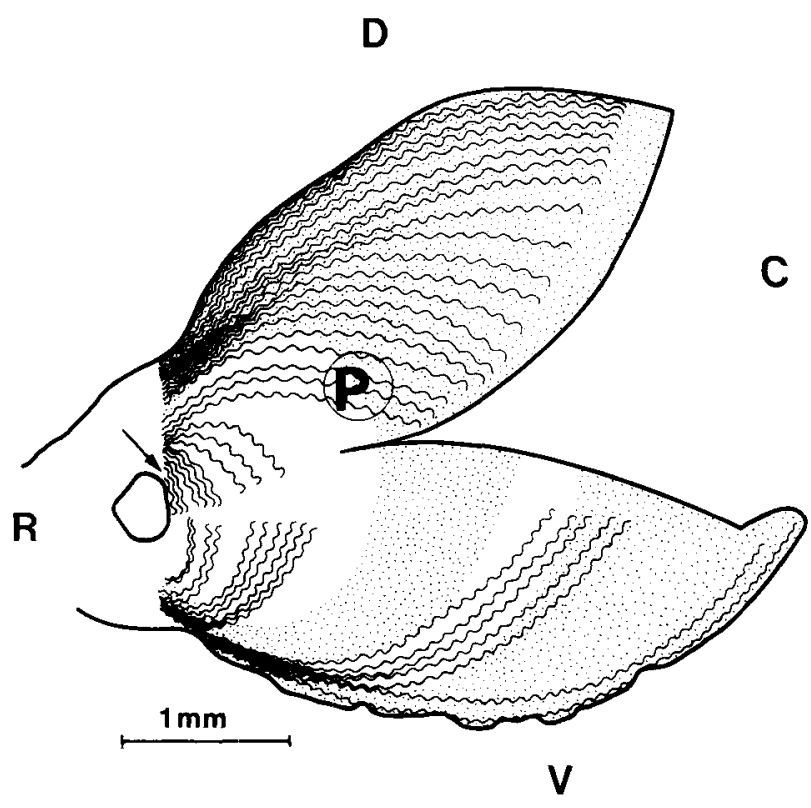

Fig. 1. Camera lucida sketch of a whole-mounted left tectal lobe. HRP had been applied to the partially sectioned right optic nerve 3 days before sacrifice. The anterogradely labeled axons in fascicles are represented by wavy lines. Regions occupied by labeled terminal arbors are indicated by stippled zones. The circle, $\mathrm{P}$, in the dorsal hemitectum shows the region from which the camera lucida tracings of subsequent Figures 2 and 4 were depicted. Arrow points to fascicle groups enlarged in Figure 3. 

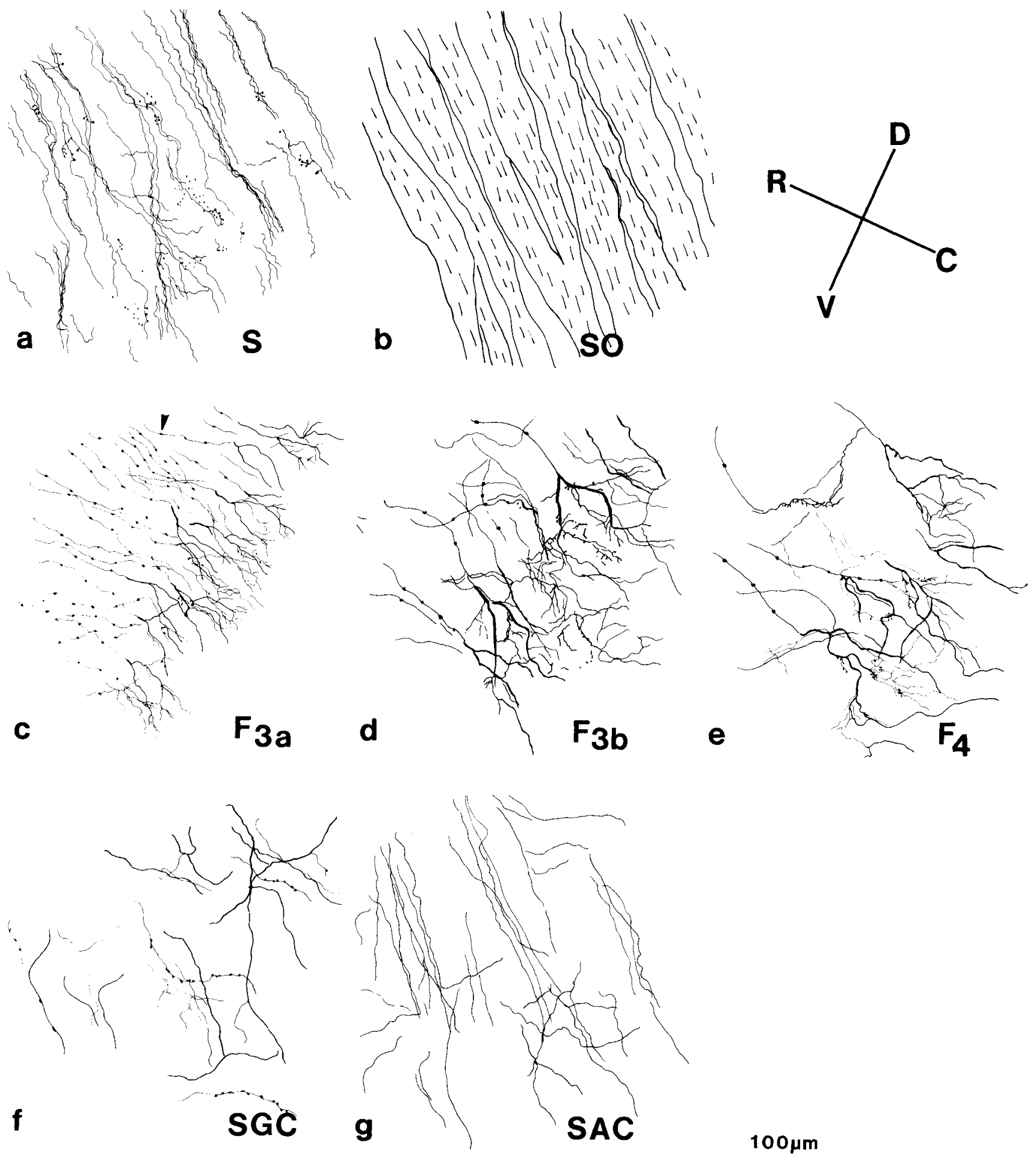

$100 \mu \mathrm{m}$

Fig. 2. Cameral lucida tracings of retinal fibers and terminals in dorsomedial tectum (region $\mathrm{P}$ of Fig. 1) in various strata, as labeled. Included were generally all labeled processes in the field of view. Only in c, just the front of terminal arbors was drawn and the dense fiber network caudal to it omitted. The orientation is the same in all figures and indicated by the cross in the upper right. The black dots in a and $f$ indicate HRP-labeled

bulbs which surrounded or were connected to labeled fibers. c-e show the front of terminal arbors emerging from rostrocaudally directed extrafascicular axons. The extrafascicular fibers in SFGS were associated by spindlelike enlargements indicated as black attachments (arrowhead in c). Note that the extrafascicular axons and terminal arbors in $c-e$ are all oriented rostrocaudally. 


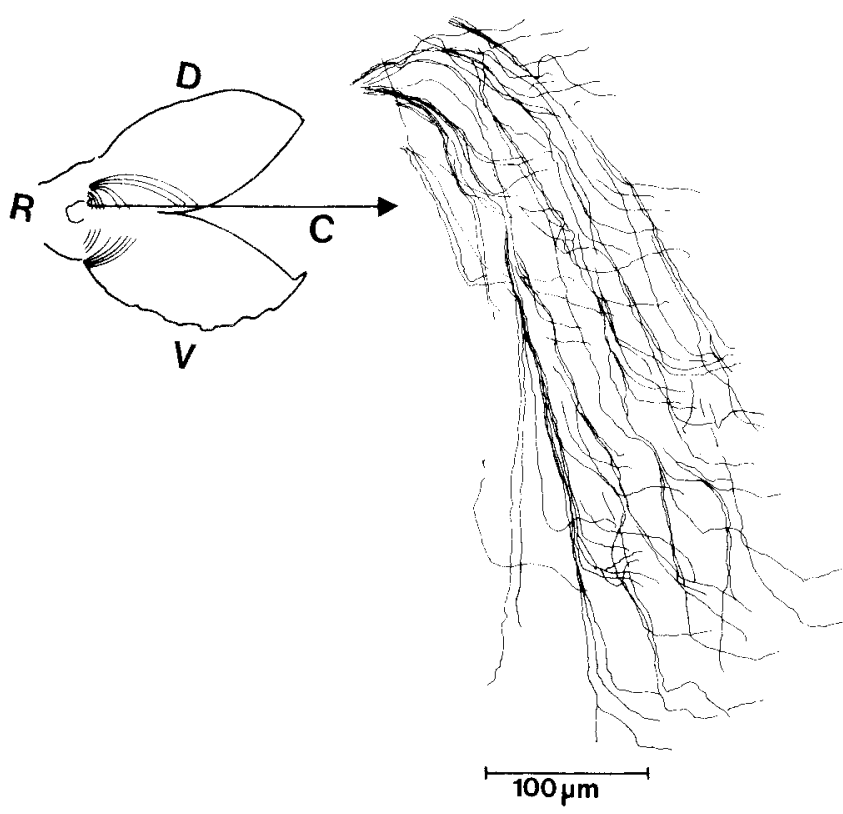

Fig. 3. Camera lucida tracing showing the course of fibers through rostral fascicles of the tectum in Figure 1 (arrow) and their sequential departure from their fascicle. The beginning of the fascicle is upward, the end at the tectal equator downward. The fascicle's origin is indicated in the sketch of tectum to the upper left. The departing fibers angle off from their fascicle and course caudally through SFGS. Not shown is that the fibers in SFGS are in a focal plane deep to those in SO. The spindlelike enlargements are omitted.

terminal arbors in region $\mathrm{P}$ of Figure 1 . A more detailed description of the spatial order of fascicular and extrafascicular axonal path, and terminal arbor position is analyzed in earlier reports (Stuermer and Easter '83, '84b; Easter and Stuermer ' 83 , '84) and in the second part of this study.

In the region $\mathrm{P}$ of Figure 1, the extrafascicular axons in $F_{3 a}, F_{3 b}$, and $F_{4}$ arrived through caudally directed routes and gave rise to their terminal arbors, which flattened and elongated within the layer in which their axon traveled, and shared a basic form (Figs. 2c-e, 4, 5, 16). The terminal portion of the stem axon had no spindles. The diameter enlarged four to six fold to form the stem segment of the arbor, which bifurcated into two major branches of equal diameter. The two major branches divided further into processes of decreasing diameter (Holland et al, '81). Sometimes, additional thin processes emerged from the stem segment. All segments of the terminal arbor were studded with swellings and protrusions. Most conspicuous were bulbs on a slender stalk (indicated by arrows in Figs. 4, 5, 16) that budded off all branches as well as occasionally from the stem segment. The significance of these appendages and swellings is uncertain.

We traced about 50 terminal arbors of this and other tectal whole mounts; camera lucida drawings are shown in Figure 4 and photomicrographs in Figures 5 and 16. Terminal arbors occur in three sizes: small (Figs. 4a,b, 5a,c); medium (Figs. 4c, 5d); and large (Figs. 4d, 5e,f). We measured the extent of numerous terminal arbors of relatively central tectal regions by encircling the complete arbor from its stem segment to its visible branches, and by determining its longest and shortest axis. The long and short axes of 34 distinct terminal arbors (all from the tectal whole amount of Fig. 1) were plotted in Figure 6. Small terminal arbors have dimensions of average $34 \times 52 \mu \mathrm{m}$ and derive from small-caliber axons. Large terminal arbors, with dimensions of average $103 \times 150 \mu \mathrm{m}$ emerge from mediumcaliber axons. Large terminal arbors from large axons with dimensions of average $158 \times 274 \mu \mathrm{m}$ are comparatively rare.

$\mathrm{F}_{3}$ had mostly small terminal arbors in its superificial tier, $F_{3 a}$, and all three sizes more deeply in $F_{3 b}$. The large terminal arbor with its stem segment in $F_{3 b}$, extended most of its processes in $F_{3 b}$, but some reached up to $F_{3 a}, F_{4}$ contained almost exclusively medium terminal arbors.

In any column perpendicular to the tectal surface, the major branches of all terminal arbors-small, medium, and large-were oriented similarly, as can be seen by comparison of Figures 2c-e. Here, in the central tectum, the long axis was always rostrocaudally oriented and derived from axons of the same orientation in SFGS. The orientation and shape of terminal arbors were different in other regions, as will be described below.

In regions with a high density of terminal arbors and fibers, individual elements were not discernable. Instead, the labeled processes formed two distinct meshworks: the upper one in $F_{3}$, the lower one in $F_{4}$. The two had very different textures. The one in $\mathrm{F}_{3}$ was very dense, as shown in Figure $7 \mathrm{a}$, whereas the one in $\mathrm{F}_{4}$ had a coarser structure (Fig. 7b). The coarseness of $F_{4}$ may be attributed to the fact that it contained predominantly medium fibers and terminal arbors in lower density than those in $\mathrm{F}_{3}$. This difference in the texture of the two neuropils matches the differences of silver grain distributions over $F_{3}$ and $F_{4}$ seen in autoradiograms (Landreth et al., '75; Stuermer, '78) as well as the different coarseness of retinal axon remnants seen with degeneration methods (Sharma, '72).

Retinal fibers in mid-SGC and SAC were more difficult to trace, because they lay in deep focal planes, but a few general statements can be made. The density of fibers in SGC and SAC was low relative to the upper layers. Similar to fibers in $\mathrm{S}$, they stained densely and homogeneously and lacked spindles. The diameters of the fibers were larger than in $\mathrm{S}$ and smaller than the large fibers in SO and SFGS. Precise measurements were not possible because of the limited visibility in the deeper layers, but diameters ranged between 0.5 and $2.5 \mu \mathrm{m}$.

In SGC, fibers traveled in various directions, often describing semicircular or circular routes (Fig. 2f). Occasionally, a fiber was seen to bifurcate. Individual terminal arbors could not be recognized. Instead, a few-not allfiber segments bore bulbs.

In SAC, many of the labeled fibers were in rostrocaudally oriented bundles (Fig. $2 \mathrm{~g}$ ), but individual fibers of different orientation and curvy routes were also present. Some fibers bifurcated. Again, terminal arbors could not be detected. A few fibers of relatively small caliber were studded with bulbs.

Because of the limited visibility in deep focal planes we cannot be sure that we saw all the labeled processes.

\section{The spatial order of retinal axons and terminal arbors}

The reliable visualization of labeled retinal fibers and their terminal arbors enabled us to use tectal whole mounts to study, in SO and SFGS, the spatial relationship of pathways and terminal arbors of axons of defined retinal regional origin. 


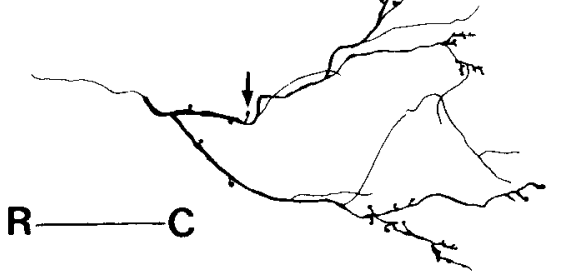

a

$50 \mu \mathrm{m}$

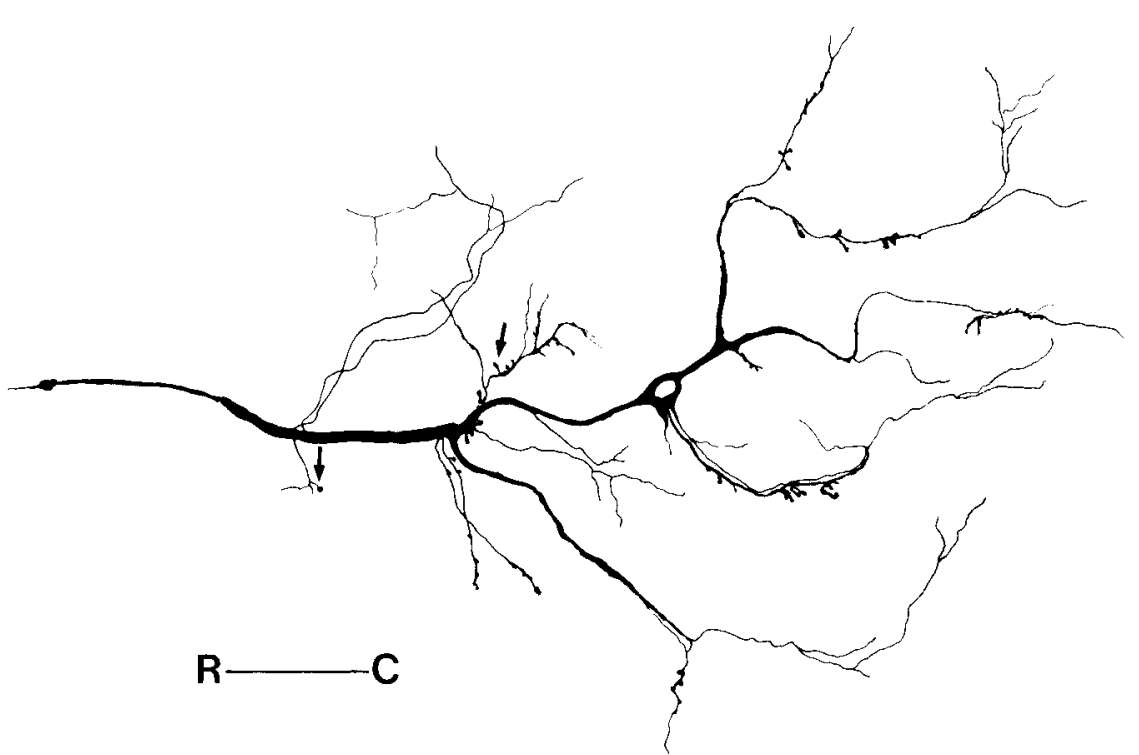

C

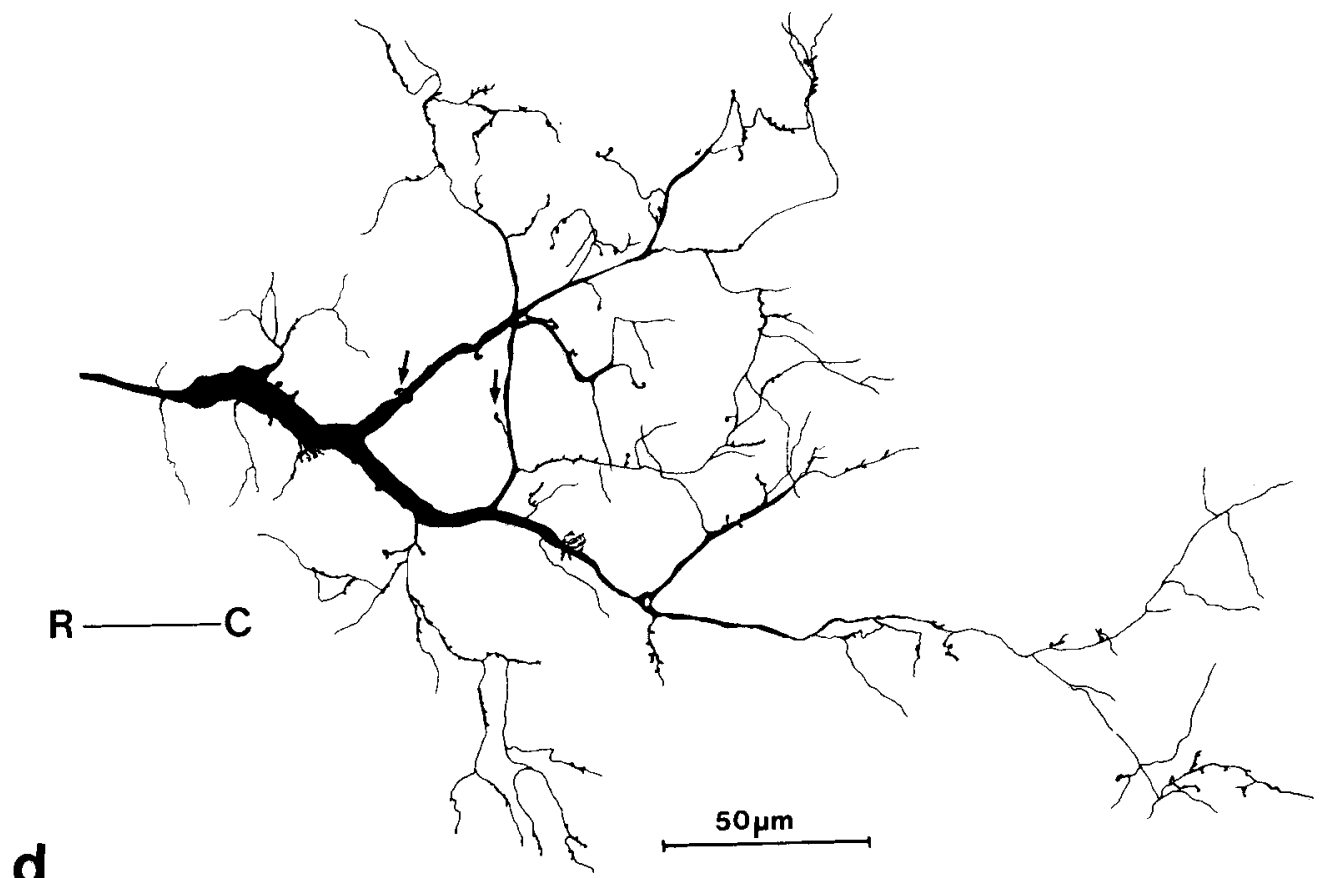

Fig. 4. Terminal arbors of (a, b) small, (c) medium, and (d) large sizes. The afferent axons enlarge in diameter to form the arbor's stem segment, which divides further into two major branches anf fine-caliber processes.

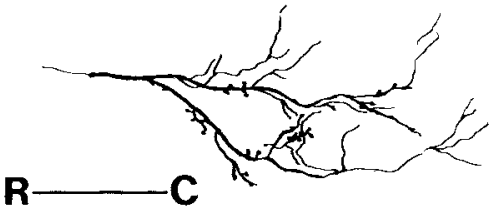

$50 \mu \mathrm{m}$ b

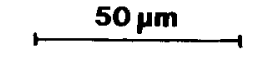
. 

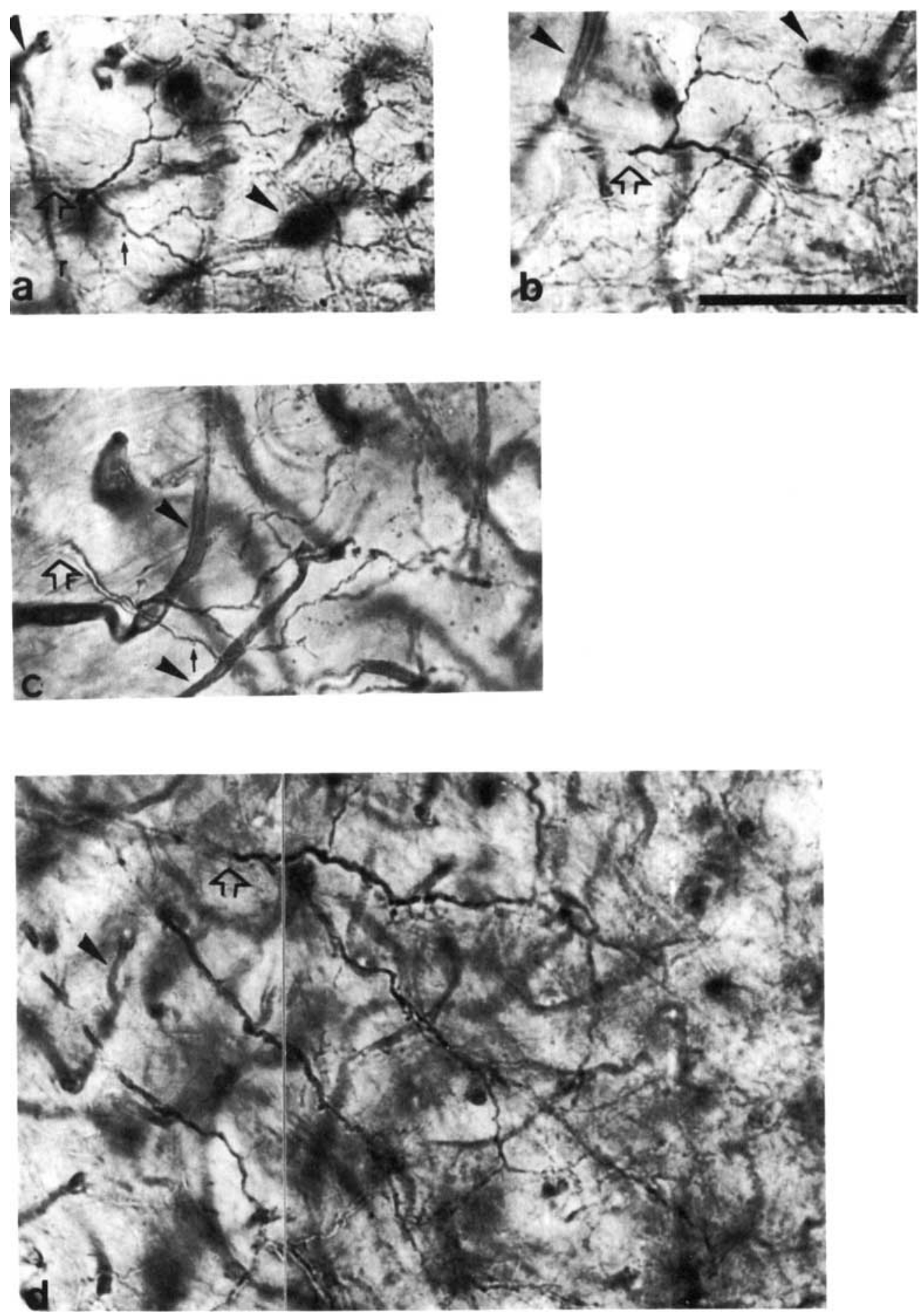

Fig. 5. Photomicrographs of HRP-stained terminal arbors of small (a-c) and medium (d) sizes and parts of terminal arbors of large sizes (e,f). Only one major branch of each of the large terminal arbors could be shown, since the other major branch extends in a different layer within SFGS and is therefore in a focal plane below the first branch. Calibration bar $=30 \mu \mathrm{m}$.

Axons of the same retinal ganglion cell generation could be labeled by penetrating the optic nerve with an HRPcoated needle (Rusoff and Easter, '80). The retinal wholemounts revealed the parent ganglion cells of the labeled axons, which lay in either an annulus or in a half-annular
The open arrows in a-e point to the arbor's stem segment which divides into two major branches. These branches can be seen to divide further into processes of decreasing diameter. Small arrows in a, c, and findicate bulbs on slender stalks. Some processes of the arbors are out of focus or partially obscured by the heavily stained bloodvessels (arrowheads).

region. The photomontage of Figure 8 depicts a segment of a typical annulus in midretinal position. The tectal wholemount revealed the location of the terminal arbors.

One retina with labeled ganglion cells in a large central annulus centered on the optic nerve head is shown in the 

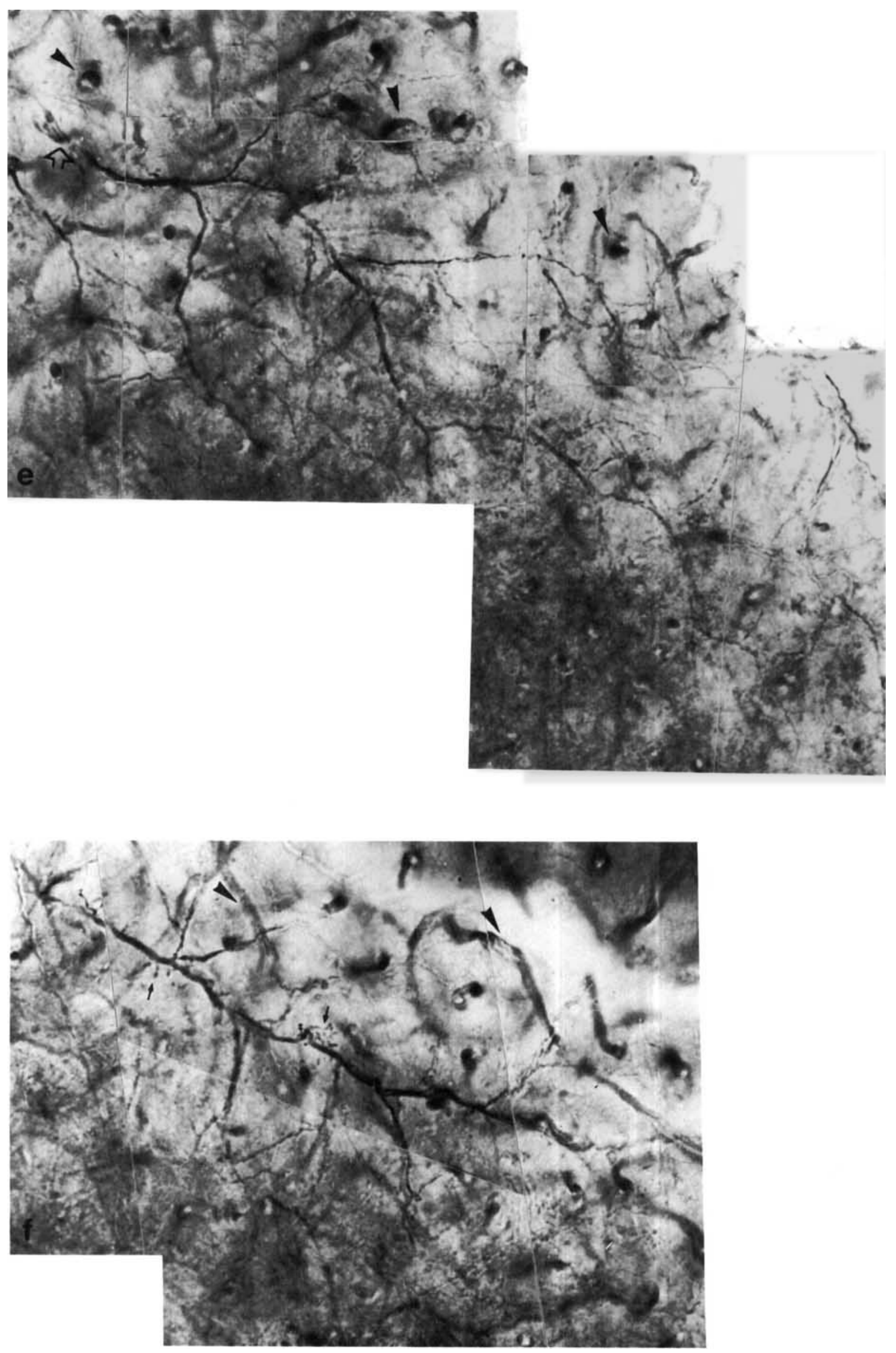

Figure 5 (continued) 


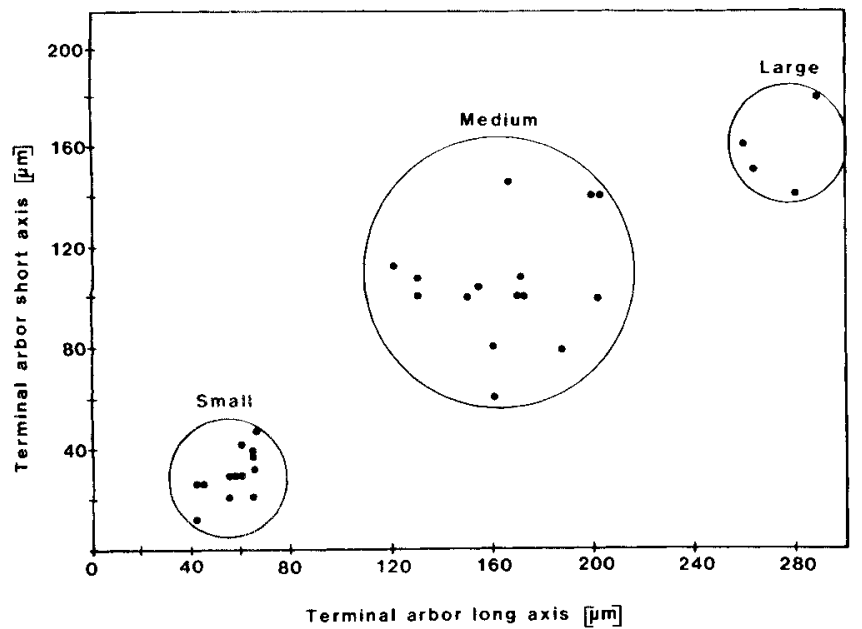

Fig. 6. In this diagram the long and short axes of 34 terminal arbors are plotted. Terminal arbors fall in three size classes which are encircled and subheaded as small, medium, and large.

camera lucida sketch in Figure 9. In the contralateral tectum, labeled fibers derived from central ganglion cells entered through short rostral fascicles into SO of both ventral and dorsal hemitectum, confirming our earlier results (Stuermer and Easter, '82, '84). Terminal arbors in SFGS occupied a large circular field in the central tectum, as conveyed by the stippled zone. (There was no region evident in the center of this field which lacked terminal arbors. This may indicate that the portion of visual space imaged on the optic nerve head is not represented in tectum, or it may only indicate that the terminal arbors are so large that the disc's representation has been obscured.)

This result shows that central retinal ganglion cells have terminal arbors in central tectum, consistent with the retinotopic map inferred from electrophysiological experiments (Meyer, '77; Schmidt et al., '78). This pattern of labeled fascicles confirms the earlier conclusion (Stuermer and Easter, '84b) that older axons enter through rostral fascicles.

The left retina shown in Figure 10 had labeled ganglion cells in a central and a peripheral annulus and a few ganglion cells in an intermediate half annulus confined to the ventral hemiretina. The right tectum, shown below, had pairs of labeled rostral fascicles in corresponding positions in the ventral and dorsal hemitectum derived from the central retinal annulus, and pairs of labeled peripheral fascicles close to the ventral and dorsal tectal margins which derived from the peripheral retinal annulus. Further, it had a few labeled fibers in a fascicle confined to the dorsomedial hemitectum, in positions intermediate to the rostral and peripherocaudal fascicles originating from the intermediate half-annulus in ventral hemiretina. This intermediate fascicle was clearly visible in rostral tectum, but caudally it contained too few fibers to determine its course with certainty.

The terminal arbors were in three distinct regions-in two annular and one half-annular field. The one annular terminal arbor field was in the central tectum, the other one in peripheral tectum adjacent to the tectal margin. The half-annular field extended in an arc in the dorsomedial hemitectum, in a position between the central and periph-

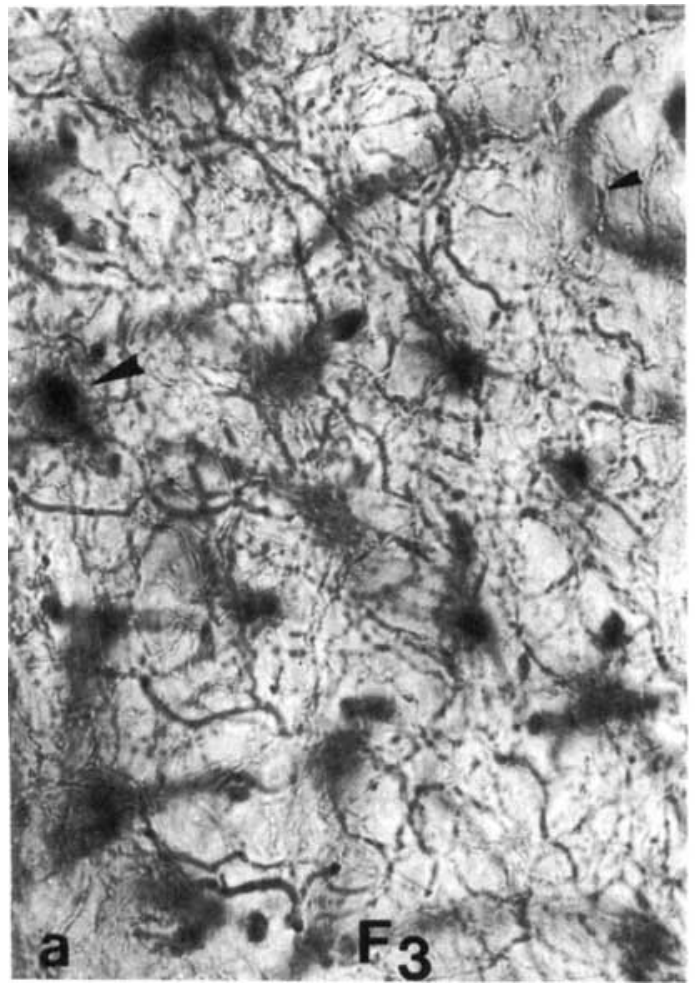

Fig. 7. Photomicrograph of the fiber network of axons and terminal arbor processes in (a) layer $F$; and (b) layer $F_{4}$. Note the denser webbing of $F_{3}$ as

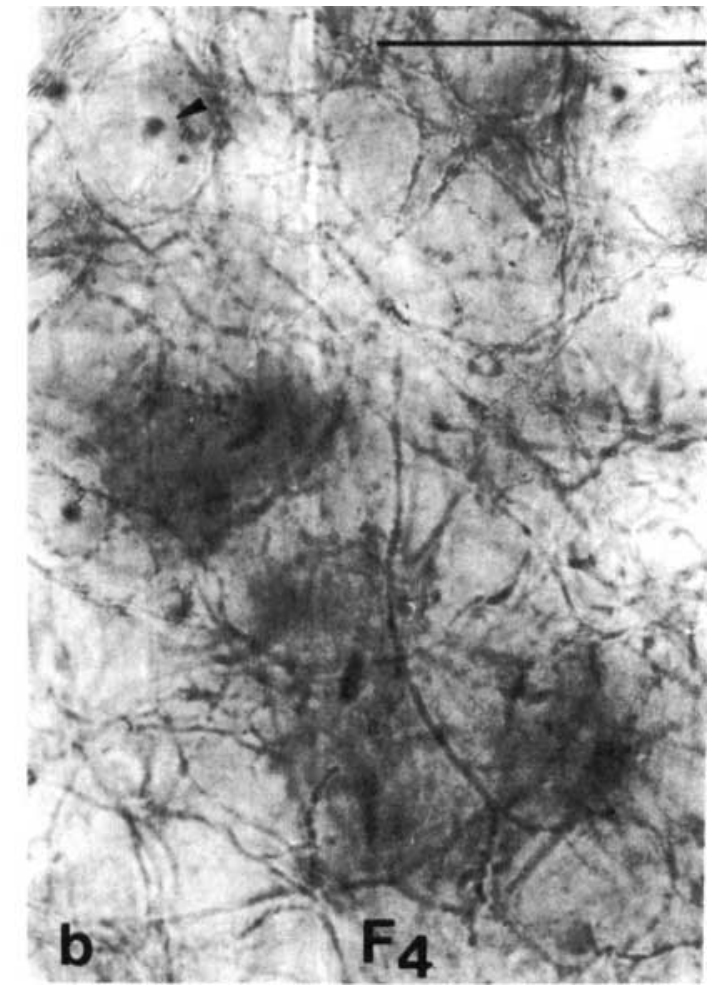

compared to $\mathbf{F}_{4}$. The dark circular and tubular features (arrowheads) are stained bloodvessels. Calibration bar $=100 \mu \mathrm{m}$. 


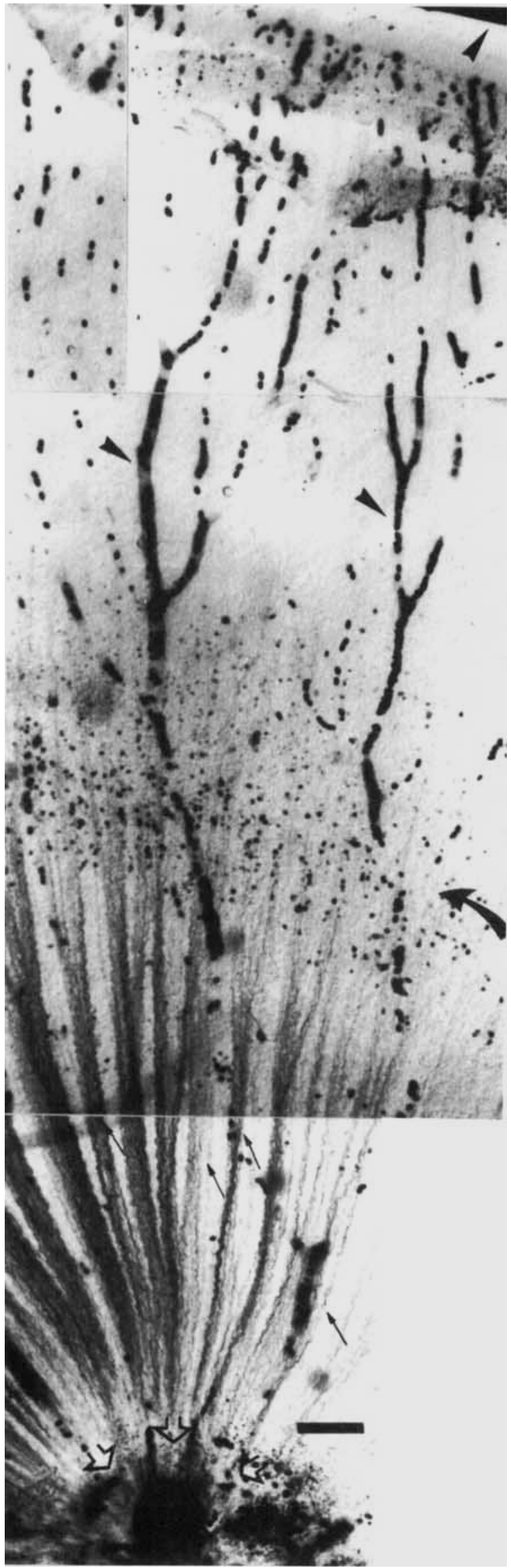

eral terminal arbor field and ended caudally at the tectal equator halfway between the tectal center and the caudal tectal pole. This half-annular region consisted of terminal arbors in a density much lower than the central and peripheral annulus.

Thus, for each labeled retinal annulus or half-annulus there were labeled annular or half-annular beds of terminal arbors in the SFGS of the tectum, positioned retinotopically. The axons in SO for these terminal arbors were clustered in fascicles according to their age-related order (Stuermer and Easter, '82, '83, '84b). These observations were confirmed in 18 additional tecta.

In Figure 11 we show the trajectories of a few examples of extrafascicular axons which feed into the SFGS of the tectum of Figure 10. Drawn were those axons which could be traced continuously over some distance to their point of arborization. Other axonal segments were not included. Details like the spindles and the detailed arborization of the terminal arbors were also omitted. The regions from which these fibers were depicted are indicated by letters a-f in the sketch of tectum. The density of extrafascicular fibers was highest in rostral tectum, since all axons departing from the rostral fascicles and those exiting rostrally from the intermediate and peripheral fascicle course together. The majority of axons crossing over the rostral tectum exhibited caudally directed routes, some straight and parallel to the tectal equator, others obliquely. In this tectum, we were not able to trace these axons individually throughout their course (however, see Easter and Stuermer, '84) but we could discern them again shortly before they entered into the bed of terminal arbors. Those giving rise to terminal arbors in the anterior portion of the annulus (a in Fig. 11) arrived through rather straight, caudally directed routes. Several extrafascicular axons in oblique routes could be followed to approach the dorsomedial and ventrolateral extremities of the central annulus. These axons, as those shown in Figure 11b, often took slightly curved routes before they reached the annular rim and terminated there. Numerous fibers passed through the anteriorly situated terminal arbors and coursed caudally toward the posterior portion of the annulus (Fig. 11c).

In the tectal periphery the extrafascicular axons between the terminal arbors and their fascicle of origin were short and could be traced from their point of exit to their terminal arbors. The extrafascicular axons from peripheral fascicles to the peripheral bed of terminal arbors are shown in Figure 11f. They departed from their fascicle rather abruptly and coursed centrally. Those leaving the fascicle at the caudal tectal pole actually had rostrally directed routes, confirming predictions by Raymond and Easter ('83).

The extrafascicular axons feeding into the intermediate terminal arbor zone between the central and peripheral annuli (Fig. 11d,e) could be seen to leave their fascicle rostrally at an angle of approximately $45^{\circ}$, and to travel aligned obliquely toward the center to the rostral portion of the terminal arbor bed (Fig. 11d). Further caudally (Fig. 11e), they first ran almost parallel with their fascicles and

Fig. 8. Photomontage of a retinal sector showing part of a midretinal annulus (arrow). The optic disc is downward, the peripheral retinal rim upward. Labeled ganglion cells are visible as small black dots. Their axons (small arrow) course towards the optic disc (open arrows, bottom of picture). Arrowheads point to the heavily stained retinal bloodvessels. Calibration bar $=100 \mu \mathrm{m}$. 


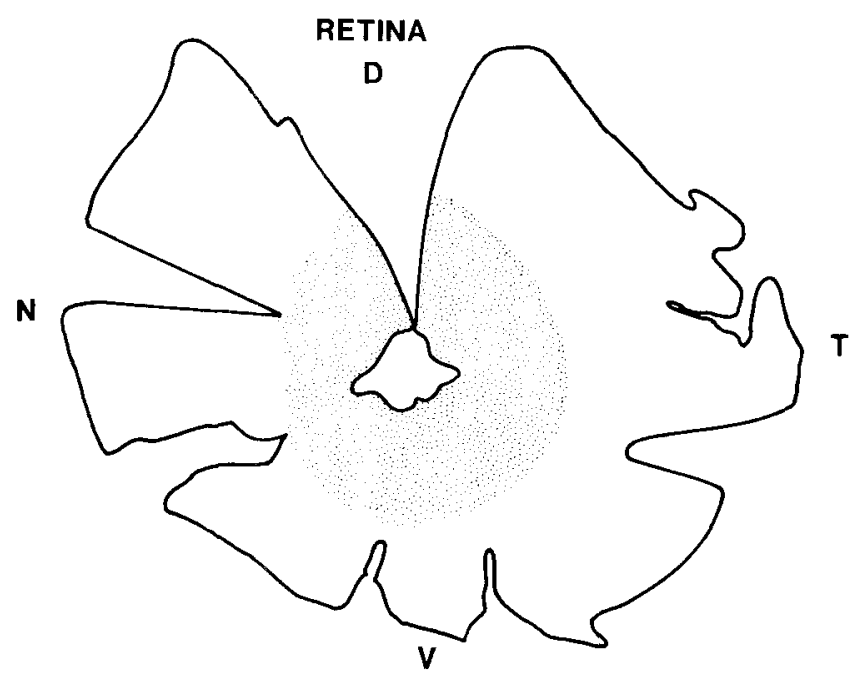

\section{TECTUM}

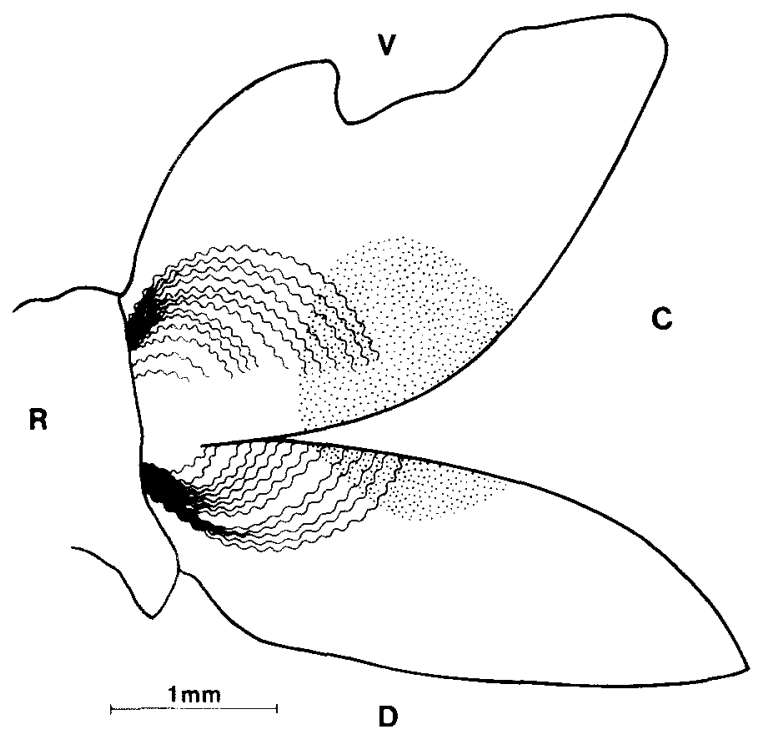

Fig. 9. Camera lucida sketch of whole-mounts of a left retina and the right tectum. Three days before sacrifice HRP had been introduced into the optic nerve. Retrogradely labeled ganglion cells indicated by stippled zone are in a large annular region in the central retina. Labeled terminal arbors (stippled zone) are in an annular zone in central tectum. The axons enter into tectum through short rostral fascicles indicated as wavy line.

curved gradually toward their terminal sites. Close to the tectal equator they turned caudally.

Another tectum (Fig. 12a) is shown to demonstrate the different directions of extrafascicular axons departing from neighboring intermediate to relatively peripheral fascicles. The region of interest is indicated by an arrow in Figure $12 \mathrm{a}$ and a few typical axons of this region are enlarged in Figure12b.

In the caudal tectum, these fascicles intersected the terminal arbor bed. Here, the terminal arbors were underneath the fascicles and connected to the fascicles by short extrafascicular axons of various directionalities. Most extrafascicular axons originating from the least peripheral
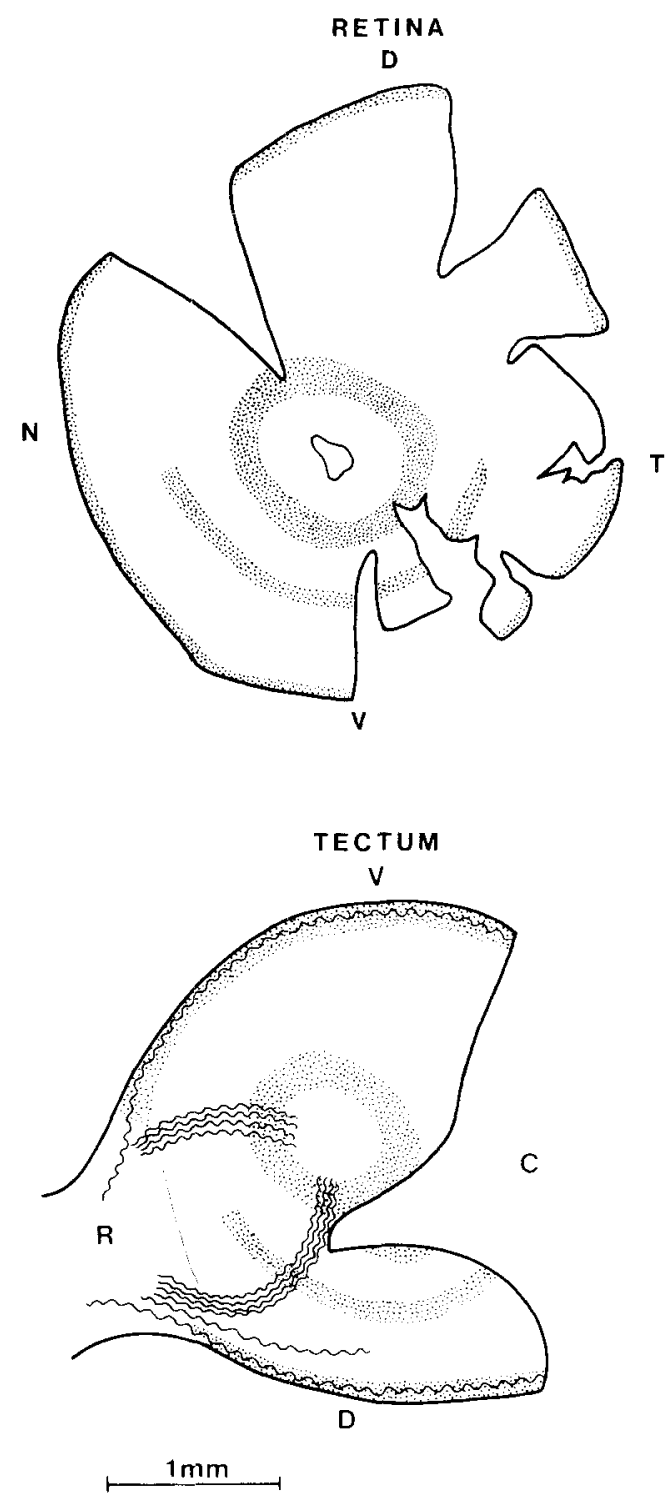

Fig. 10. Camera lucida sketch of a left retina and right tectum of an animal whose nerve had received HRP 3 days before sacrifice. Labeled ganglion cells in retina (stippled zones) were in a peripheral and central annulus and in an intermediate half-annulus in ventral hemiretina. In tectum terminal arbors (stippled zones) were in a peripheral and a central annular region and in a narrow half-annular zone between central and peripheral annulus in dorsomedial hemitectum. Labeled axons (indicated as wavy lines) were in pairs of short rostral fascicles, in pairs of long peripherocaudal fascicles, and in unpaired intermediate fascicles in the dorsal hemitectum.

fascicle turned caudally and gave rise to terminal arbors slightly caudal from the fascicle. However, several extrafascicular axons in this region were observed in oblique and curved routes. Some even exhibited $360^{\circ}$ loops before they gave rise to their terminal arbor next to their fascicle of origin, as is shown in the camera lucida drawing in Figure $12 \mathrm{~b}$. In this figure, the fibers in fascicles in $\mathrm{SO}$ are indicated running from left to right (toward the tectal equator). The extrafascicular axons in SFGS are drawn in the same plane. Those extrafascicular axons whose origins were the more 

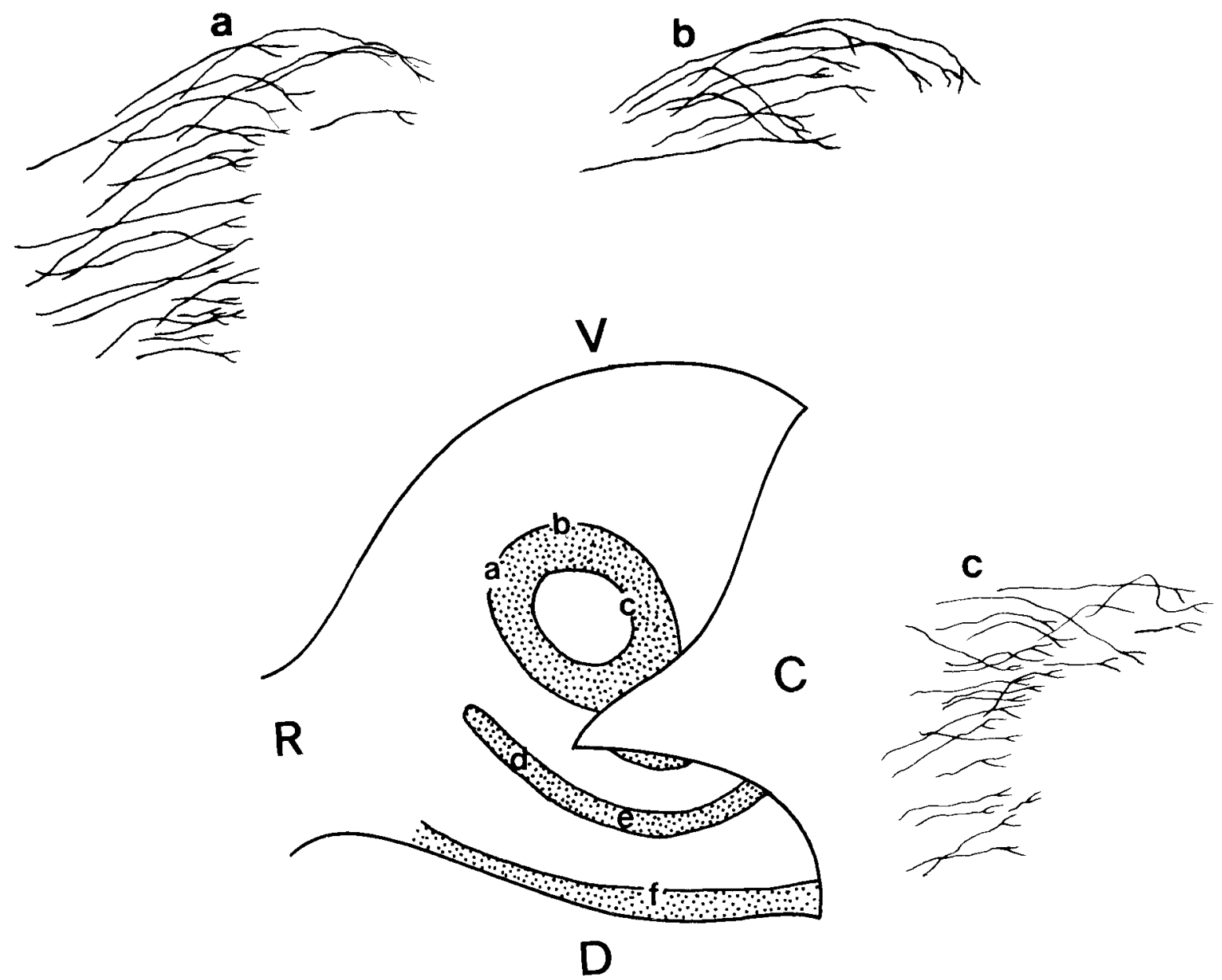

$1 \mathrm{~mm}$
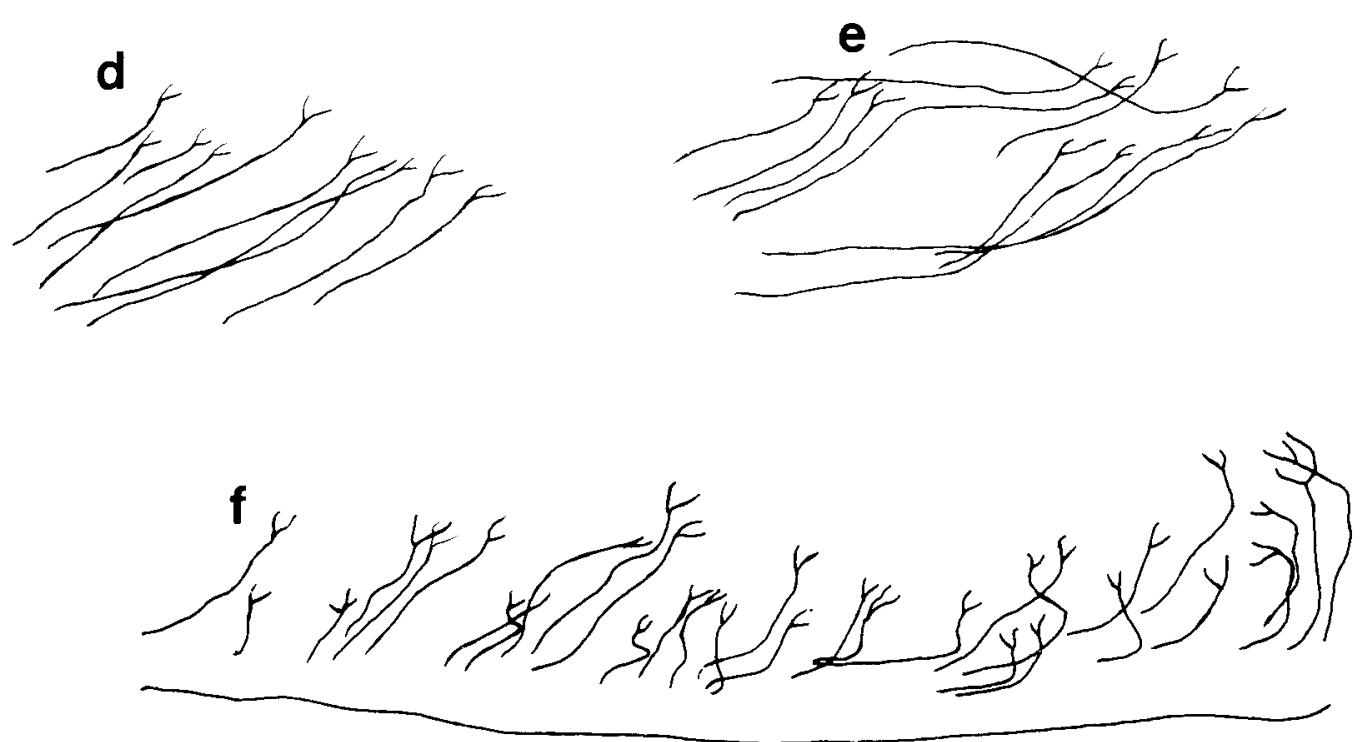

Fig. 11. Composition of camera lucida sketches showing extrafascicular axons entering into three different terminal arbor regions of the tectum of Figure 10. Three terminal arbor zones in tectum are outlined. The letters a-f in the tectum indicate the regions which were approached by the extrafascicular axons represented in sketches a-f. Note the different orientation of extrafascicular axons into different regions. 


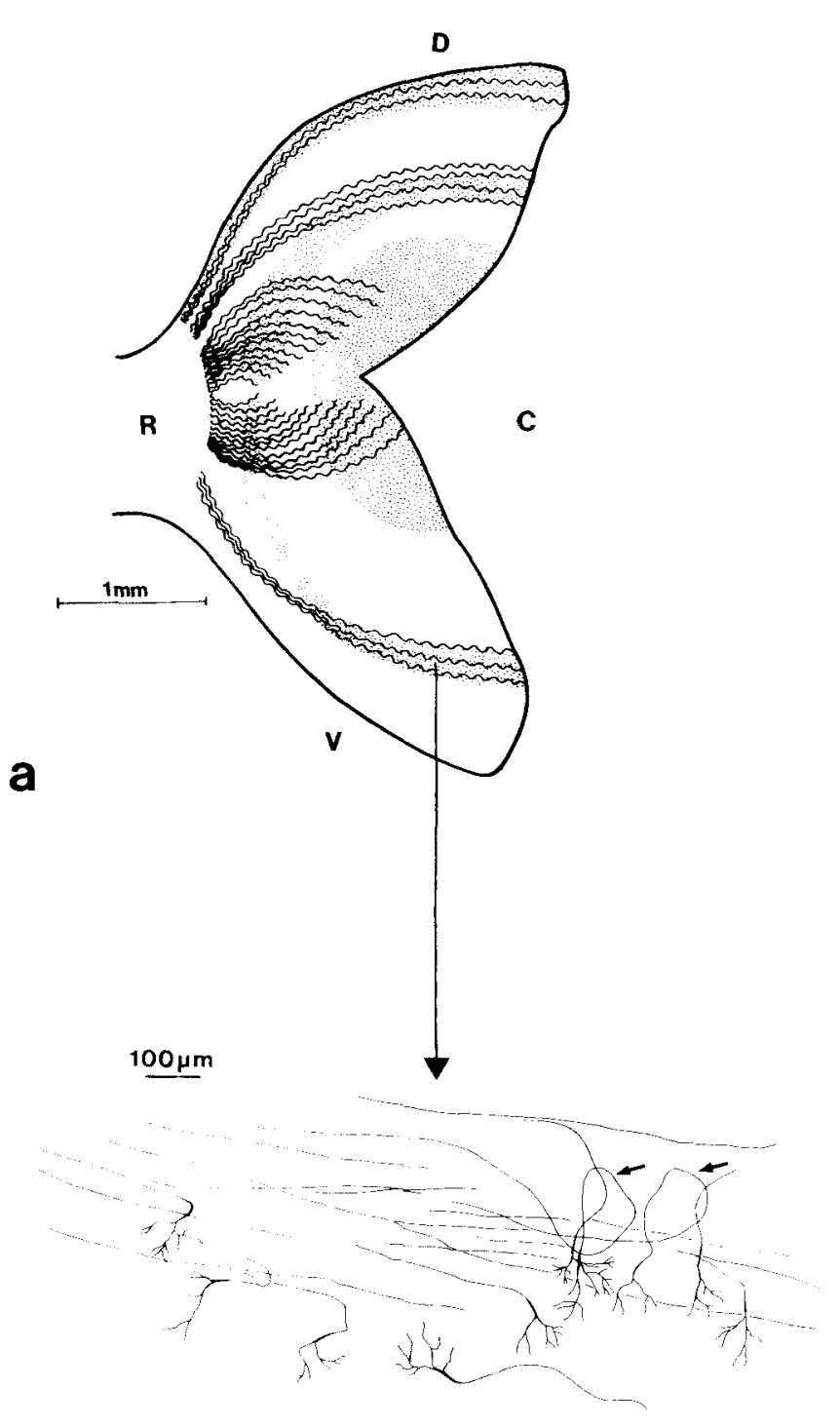

b

Fig. 12. a. Camera lucida sketch of a tectum with three terminal arbor fields (stippled zones) and labeled fibers in rostral, intermediate, and peripherocaudal fascicles (wavy lines). Examples of fiber trajectories and terminal arbors of a region in ventrocaudal hemitectum are represented in $12 \mathrm{~b}$, as indicated by the arrow. b. Camera lucida tracings of fiber trajectories and terminal arbors from a tectal region in a. Fibers in fascicles are shown as lines coursing from left to right. Most extrafascicular axons departing from the fascicle have short caudally directed routes before they deploy their terminal arbor in caudal orientation. Two extrafascicular axons (arrows) describe $360^{\circ}$ loops before they deploy their terminal arbors.

peripheral fascicles were centrally directed, deploying their terminal arbors centrally from their fascicles, similar to extrafascicular axons departing from the marginal fascicles.

The extrafascicular paths meet the predictions conveyed in models on retinotectal growth (Raymond and Easter, ' 83 ; Easter and Stuermer, '84). They are long and caudally directed for terminal arbors in central tectum deriving from rostral fascicles, and short and centrally directed for terminal arbors at the tectal margin, deriving from peripheral fascicles. They are of variable directions and length for terminal arbors between the central and peripheral arbor beds, and generally longer rostrally than caudally.

\section{Variation in orientation and shapes of terminal arbors}

Terminal arbors differed strikingly from one another in orientation and shape, depending on the tectal position. This variability was observed for all three types of terminal arbors. Figures 13-15, tracings of medium terminal arbors from one tectum, illustrate these differences. The terminal bulbs and swellings were not drawn.

Terminal arbors in the central tectum are shown in Figure 13. Their position is indicated by numbered circles in the sketch of the tectum. They all emerged from caudally directed extrafascicular axons derived from short rostral fascicles. The thick stem segment of the arbor extended in the same direction as the afferent extrafascicular axon. The two major branches were also predominantly caudally directed, but the finer shorter branches diverged in various directions. Thus, the terminal arbors had an elliptical shape with a pronounced long axis parallel to the tectal equator (see also Fig. 16a). The terminal arbors described in the first part of the paper (Fig. 4) were also from similar central tectal regions.

Terminal arbors in the tectal periphery, derived from the peripheralmost fascicle, are shown in Figure 14. Most arose from short, centrally directed extrafascicular axons, and most stem segments were also centrally directed. The two major branches diverged more widely than in central tectum. Often the major branches were perpendicular to the stem segment and somewhat parallel with the tectal margin.

Figure 15 illustrates terminal arbors from intermediate fascicles. In rostral tectum (Nos. 1 and 2) they arose from extrafascicular axons which angled off from the fascicle as described above. These terminal arbors had elliptical shapes, similar to those in the central tectum, with long stem segments and major branches extending in the same caudocentral direction as the extrafascicular axons.

Terminal arbors in caudal tectum belonging to similar fascicles did not share a common shape. Close to the tectal equator, many extrafascicular axons and terminal arbors had caudal orientations like those shown in Figure 11f. Off the equator, terminal arbors emerged from extrafascicular axons of various orientation (Fig. 15, Nos. 3-5). In most cases the arbor's stem segment was not oriented in the same direction as the preterminal axon. The stem segments were caudally or rostrally or centrally directed. Further, the major branches exhibited no common orientation. They often were widely set apart (indicated by two arrows in Fig. 16d) or even curved back toward the stem segment. In several instances one or both major branches came to lie next to the stem segment.

These observations on the variability of the terminal arbor shape suggest that the directions of the stem segment and the major branches are not rigidly fixed.

\section{DISCUSSION}

The major issue of the first part of this investigation is the identification of terminal arbors of retinal ganglion cell axons and their lamination in SFGS.

Terminal arbors in goldfish exhibit a similar morphology and comparable sizes as the "widely branched (WB)" and "densely branched (DB)" terminal arbors in amphibians (Potter, '72). In goldfish as in amphibians, terminal arbors 

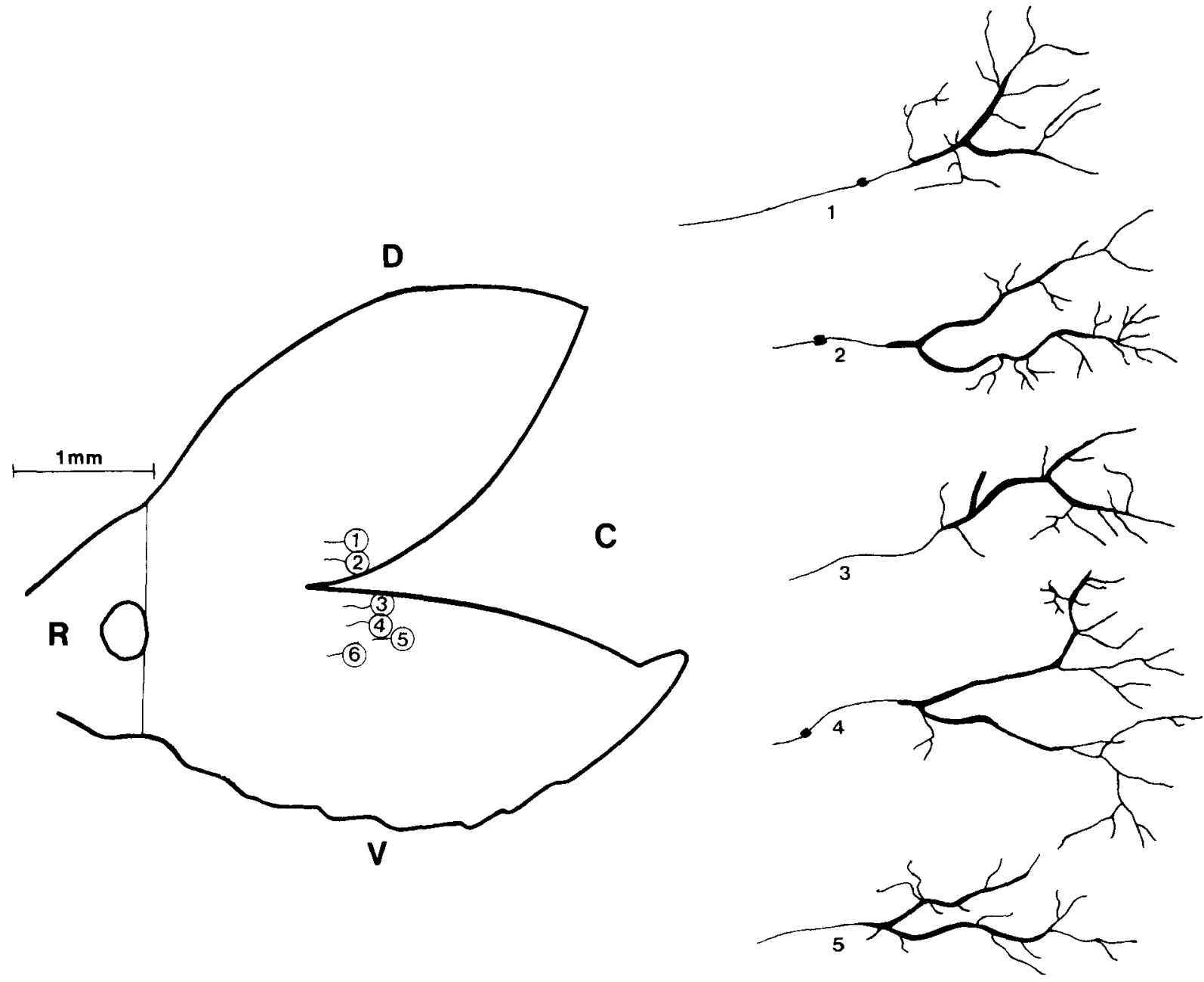

$100 \mu \mathrm{m}$

Fig. 13-15. These figures show terminal arbors of different tectal regions. In each figure, the position of the terminal arbors is marked by numbered circles in the sketch of tectum. The orientation of the extrafascicular axons for each terminal arbor is represented by short lines connected to the circles. The terminal arbors themselves and short segments of their extrafascicular axons are shown in detail in higher magnification. The

are flattened and extend horizontally (that is, parallel to the surface of the tectum), which differs from terminal arbors in the tectum of birds and mammals, where they extend vertically (Ramón y Cajal, '52).

Whole-mounts revealed a layering of fibers and terminal arbors in the three sublamina of SFGS: $F_{3 a}, F_{3 b}$, and $F_{4}$. Our present results suggest three fiber groups with different terminal arbors. Physiologically, however, only two classes of fibers terminating in SFGS were recognized: those with slower conduction velocities below others with faster numbers at each terminal arbor refer to the numbered circles in the sketch of tectum.

Fig. 13. Six terminal arbors in central tectum. They arise from caudally directed extrafascicular axons. Their stem segment and the major branches are caudally oriented, such that the arbors exhibit elliptical shape.

conduction velocities (Schmidt, '79), so that one morphologically distinct axon group remained physiologically undetected.

Earlier work by Jacobson and Gaze ('64) has characterized the receptive field properties of axons terminating in SFGS. "On," "off," and "on-off" responses were recorded in SO and the upper layer of SFGS, with a predominance of brief "on-off" responses. In the deeper layer of SFGS corresponding to layer $F_{4}$, sustained "on" and "off" responses predominated. Thus, the anatomical separation between $F_{3}$ 


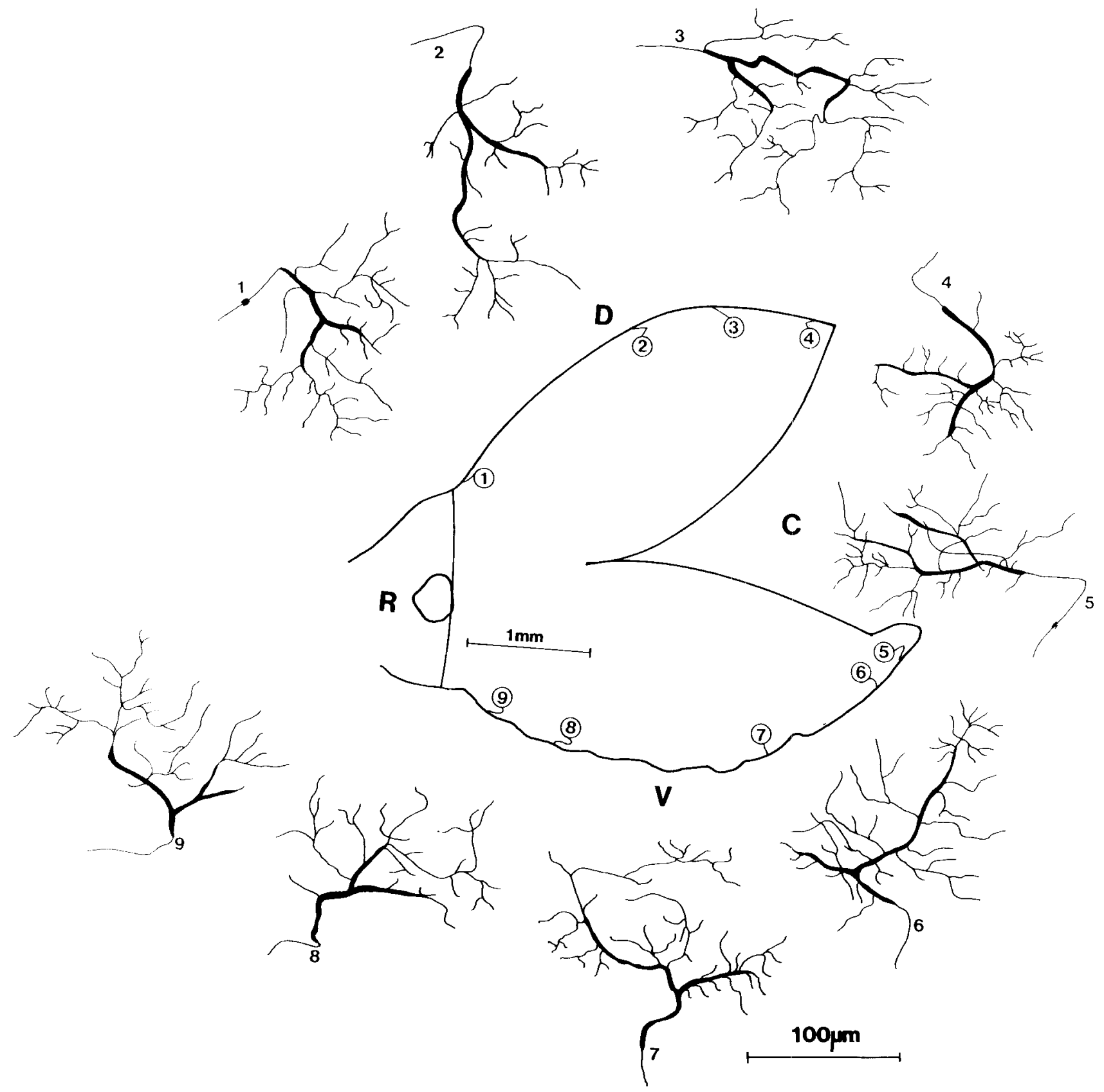

Fig. 14. Nine terminal arbors in peripheral tectum, most emergins from centrally directed extrafascicular axons. The stem segment of most terminal

arbors is centrally oriented (except Nos. 3,4 ). The major branches diverge widely and are often perpendicular to the stem segment (Nos. 1,6-9).

and $\mathrm{F}_{4}$ is paralleled by a functional separation. As yet, however, no correlation between individual terminal arbors of different morphology and their functional properties exists.

There is broad general agreement on the lamination of retinal axons in the goldfish optic tectum (Lehissa, '55 Landreth al., '75; Meyer, '80; Schmidt, '79; Sharma, '72; Springer and Gaffney, '81; Stuermer, '78; Stuermer and Easter, ' $84 a$ ). The present tectal whole-mount study revealed that fibers in different layers of the tectum exstablish characteristic fiber networks.
Despite their distinct morphologies not much information is available about the functional properties of fibers in the minor retinorecipient layers $\mathrm{S}, \mathrm{SGC}$, and SAC. Fibers in layer $\mathrm{S}$ have, to our knowledge, not been characterized physiologically. Fibers in SGC and SAC are reported to have slower conduction velocities than fibers in SO and SFGS (Schmidt, '78). But a further study on their functional characterization has not been carried out, so that the significance of these retinal afferents remains unknown.

The second part of the present study analyzed the order of retinal axonal terminal arbors, their relation to the in- 

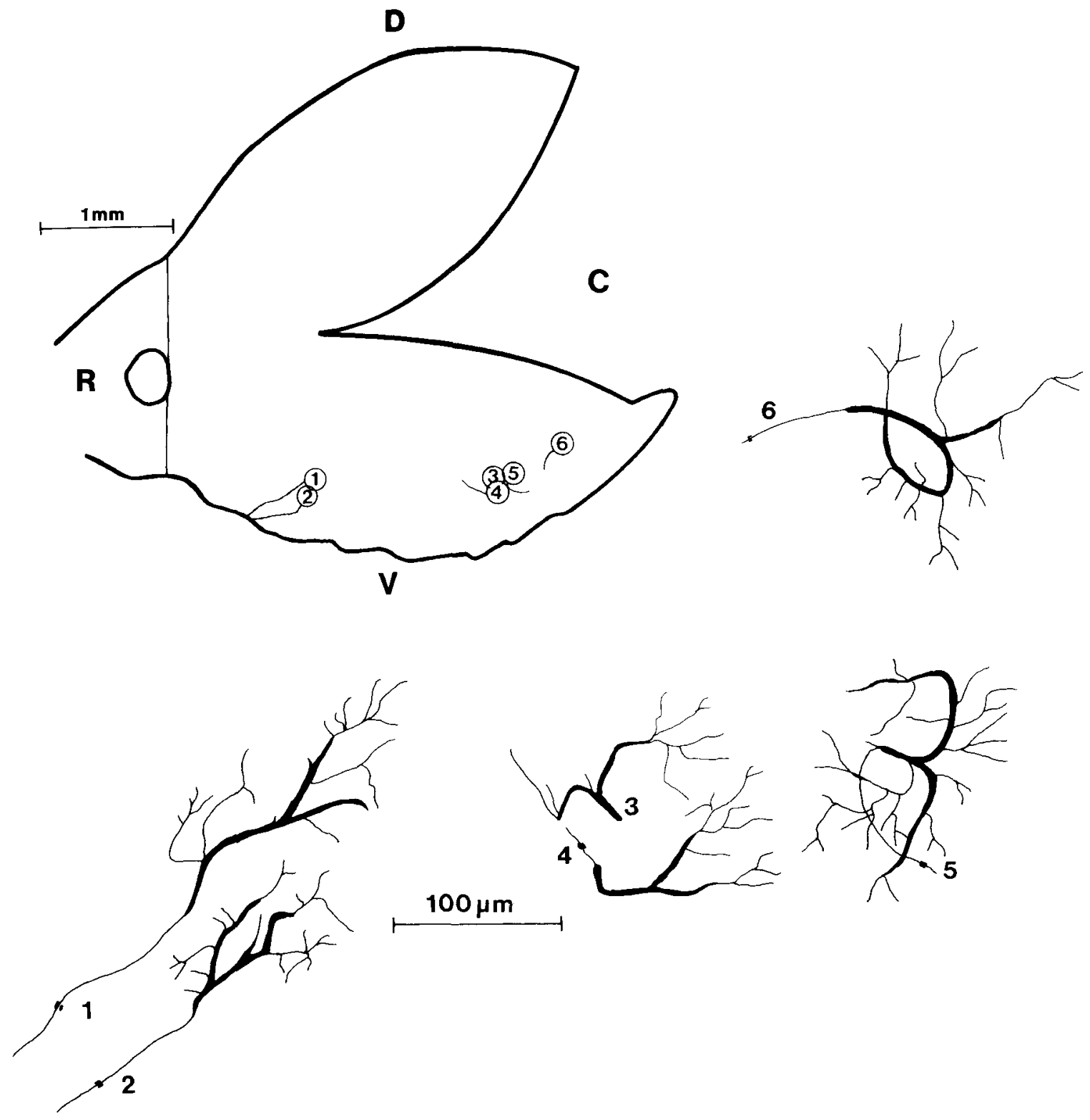

Fig. 15. Terminal arbors in intermediate regions between center and periphery. The terminal arbors 1 and 2 in rostral tectum arise from extrafascicular axons obliquely aligned toward the center. The arbors' stem segments and major branches are of the same orientation as their afferent

extrafascicular axon. These terminal arbors have elliptical shapes. The terminal arbors 3-6 in caudal tectum arise from extrafascicular axons of various directions. The initial segment and major branches have no obvious regular orientations and exhibit tortuous shapes.

tratectal axonal pathways, and the variation of terminal arbor shapes. The present findings substantiate an earlier model on retinotectal growth (Raymond and Easter, '83; Easter and Stuermer, '84) and contribute further evidence for shifting terminal arbors.

We have documented that terminal arbors in SFGS derived from ganglion cells in annular or half-annular regions in retina occupy annular or half-annular zones in tectum. The terminal arbors of half-annuli were confined to the dorsomedial or ventrolateral hemitectum corresponding to their origin from ventral or dorsal retinal ganglion cells, respectively. In retina, old ganglion cells from early generations lay close to the retinal center and ganglion cells of later growth waves lay more peripheral and concentric with the older generations (Johns and Easter, '77; Meyer, '78).

The present results showed that the terminal arbors in tectum are ordered similarly in a retinotopic array. This retinotopic organization of terminal arbors agrees with a recent whole-mount study by Rusoff in cichlids (Rusoff, ' 84 ). It further resembles the terminal arbor order in frogs, reported by Constantine-Paton et al. ('83).

This order of terminal arbors was anticipated in our earlier study (Stuermer and Easter, '83; Easter and Stuermer, '83, '84), since the retinotopic map requires that terminal arbors reside in positions that correspond topographically to the position of their parent ganglion cells. The present results substantiated our expectations.

In earlier work (Stuermer and Easter, '83, '84b) we had assumed that each terminal arbor generation initially terminates next and central to its fascicle of entrance (as is 

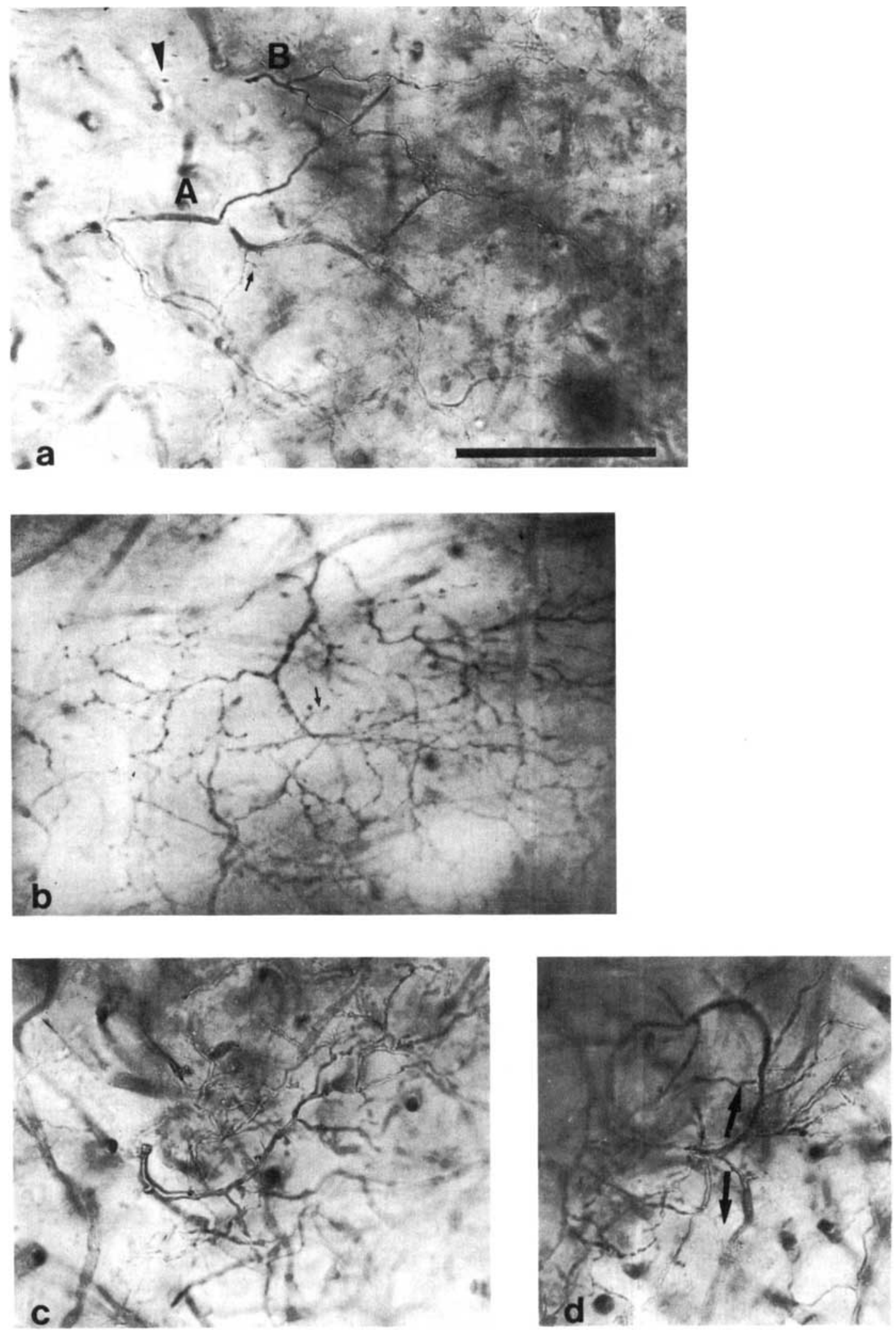

Fig. 16. Photomicrographs of terminal arbors in central (a), rostropheripheral (b), and intermediate caudal regions (c, d). Calibration bar $=100 \mu \mathrm{m}$ a. Figure 16a shows two terminal arbors, the one of large (A), the other of small size (B). The extrafascicular axon giving rise to the small terminal arbor is visible (arrowhead). It courses in caudal direction. The stem segments and both major branches of $\mathrm{A}$ and $\mathrm{B}$ are oriented rostrocaudally. b) This large terminal arbor is the same as illustrated in Figure 14 No. 1 . The stem segment is out of focus. The two major branches and the fine-caliber

processes diverge widely and extend somewhat parallel to the tectal rim. c, d. These two tortuous terminal arbors are represented in Figures 13 Nos. 4 and 5. Note the crooked stem segment of the terminal arbor in $c$. Note the crooked stem segment of the terminal arbor in c. Only one major branch is visible; the other is out of focus. The terminal arbor in d exhibits two major branches (arrows) which are oriented in opposite directions. 'The stem segment is barely visible. 
exemplified in any tectum by the most recently added axons at the peripheral tectal margin). Then-while the tectum enlarges-the terminal arbors abandon their old sites to shift to new retinotopically correct sites in the larger brain. The fascicles, therefore, mark the original locations of their terminal arbors.

It was expected (1) that most terminal arbors have to shift caudally, since new tectal space is only added caudally, (2) that the terminal arbors departing from their fascicle in rostral tectum generally have to shift farther than those in caudal tectum, and (3) that the shift is the longest for the oldest axon generations. The current results on the caudal displacement of terminal arbors from central and intermediate ganglion cells relative to their rostral and intermediate fascicle are consistent with this concept. Further, the distances of the terminal arbors to their fascicles were larger for the terminal arbors of old generations than for younger generations. Cook et al. ('83) recently published data which are in agreement with these results. Following the extrafascicular axons which link the fascicular axons and the terminal arbors allowed us to demonstrate the different terminal arbor shifts directly. These pathways match closely those shown diagrammatically in the model in Easter and Stuermer ('84).

A different direction of movement was anticipated for terminal arbors from younger generations (peripheral retina), especially in caudal tectum. The direction and length of the shift were predicted in earlier reports by Raymond and Easter ('83) and Easter and Stuermer ('84). The predictions resulted from a quantitative consideration on the (asymmetrical) retinal and tectal growth and the maintenance of the retinotopic map. Raymond and Easter ('83) calculated that $100 \%$ more axons have to squeeze into a field that augmented by only $27 \%$. Therefore, for those peripheral terminal arbors a centrally directed movement was expected. This includes, furthermore, that the terminal arbors in caudal tectum move opposite to the growing tectal border ("because the pressure to squeeze more terminals into a confined space overwhelms the tendency to spread into new territory") (Raymond and Easter, '83). This centrally directed component of terminal arbor shift is demonstrated here by extrafascicular axons departing from peripheral fascicles in Figures $11 \mathrm{f}$ and 14.

The continuous movement of terminal arbors departing rostrally in the caudal direction and the concurrent invasion of new terminal arbors pushing in centrally implies the existence of a zone in caudal tectum where the caudal and central components of movements meet. Such a zone was illustrated in Figure 12. Here, the terminal arbors lay just underneath their fascicle and were connected by extrafascicular axons of various directions. Also circular routes of extrafascicular axons were observed, suggesting that this zone might represent a transition zone in which the terminal arbors have shifted from a position central to their fascicle to a position just caudal to it.

The evidence for shifting terminals was augmented by the shapes of terminal arbors in various tectal regions. We demonstrated that terminal arbors in central tectum and those deriving from intermediate to peripheral fascicles in rostral tectum exhibit the same orientation of their stem segment and their major branches as their afferent extrafascicular axon. That is, the terminal arbors appear elongated into the direction into which they had shifted.

Terminal arbors of axons in the tectal periphery, that is, those which just recently had arrived, were central and closer to the exit from their fascicle of origin and had different shapes. Their extrafascicular axons and stem segments in most cases pointed centrally and one or both major branches were parallel to the tectal rim and perpendicular to the stem segment. The terminal arbors in the caudal tectal regions, where the caudally and peripherocentrally directed components of movements meet, exhibited various orientations of their stem segments and branches, suggesting that their shape is a result of their short-range nonuniform movement in various directions. They are likely to represent those terminal arbors which alter gradually their directionality from a central to a caudal orientation.

The mechanism by which terminal arbors actually move remains unknown. The most likely possibility is that the arbor might sprout new branches which establish connections with new postsynaptic tectal cell processes. Some of the new connections may be more appropriate than others or older ones so that the new appropriate ones may be strengthened and survive, while inappropriate ones are weakened and eventually lost, as is suggested for the reestablishment of retinotectal connections during regeneration (Fujisawa et al. '81). Such a mode of arbor plasticity could account for the observed variability of arbor shape as well as its gradual movement. It supposes also that during retinotectal growth one arbor may encounter completely different tectal cell processes. Arbors of ganglion cell axons of early retinal growth waves, for instance, will first have contacted very rostral tectal cells-when the tectum was still smaller-but then connect to cells in the center of the enlarged tectum. These central tectal cells did not even exist at the time when the axons first grew in.

The possibility that tectal cells may move with the arbor is unlikely, since Raymond et al. ('83) in their study on tectal growth have demonstrated with thymidine autoradiography the relative constancy of the position of the labeled cells. As a third possibility one might consider that terminal arbors remain connected to their dendrites, while they may drift caudally and the somata of the tectal cells stay in place. In this case, one would expect a drastic bending of the dendritic trees in the direction of the terminal arbors' shift, which we never observed and which has never been reported to exist in Golgi studies (Romeskie and Sharma, '79).

\section{ACKNOWLEDGMENTS}

This work was supported by EY-00168 to Dr. S.S. Easter, Jr., and DFG Stu 112 to C. Stuermer.

I am most grateful to Dr. Easter in whose laboratory part of this work was carried out, for his hospitality and helpful discussions. I further thank Drs. S. Easter, A. Rusoff, and $\mathrm{S}$. Thanos for reading the manuscript. I thank Mr. B. Bratton, Mrs. G. Weinraub, and Mrs. R. Groemke-Lutz for technical assistance, and Mrs. K. Ralinofsky for typing the manuscript.

\section{LITERATURE CITED}

Adams, J.C. (1977) Technical consideration on the use of horseradish peroxidase. Neuroscience 2:141-146.

Attardi, D.G., and R.W. Sperry (1963) Preferential selection of central pathways by regenerating optic fibers. Exp. Neurol. 7:46-64.

Coleman, D.R., F. Scalia, and E. Cabrales (1976) Light and electron microscopic observations on the anterograde transport of horseradish peroxidase in the optic pathway in the mouse and rat. Brain Res. 102:156163 . 
Cook, J.E., E.C.C. Rankin, and H.P. Stevens (1983) A pattern of optic axons in the normal goldfish tectum consistent with the caudal migration of optic terminals during development. Exp. Brain Res. 52:147-151.

Constantine-Paton, M., E.C. Pitts, and T.A. Reh (1983) The relationship between retinal axon ingrowth, terminal morphology, and terminal patterning in the optic tectum of the frog. J. Comp. Neurol. 218:297313.

Easter, S.S., Jr., and C.A.O. Stuermer (1982) Evidence for naturally occurring movements of retinotectal terminals in goldfish. Neurosei. Abstr. 8:745.

Easter, S.S., Jr, and C.A.O. Stuermer (1983) Establishment and mainte nance of the retinotectal projection in goldfish. Invest. Ophthalmol. Vis Sci. [Suppl.|24:8

Easter, S.S., Jr, and C.A.O. Stuermer (1984) An evaluation of the hypothe sis of shifting terminals in the goldfish optic tectum. J. Neurosci. 4:10521063 .

Fraser, S.F. (1983) Hiber optic mapping of the xenopus visual system: Shif of the retinotectal projection during development. Dev. Biol. 95:505511.

Fujisawa, H., K. Watanabe, N. Tani, and Y. Ibata (1981) Retinotopic analy sis of fiber pathways in amphibians. I. The adult newt Cynops pyrrho gaster. Brain Ress. 206:9-20.

Gaze, R.M. (1958) The representation of the retina on the optic lobe of the frog. J. Exp. Physiol. 43:209-214.

Gaze, R.M., M.J. Keating, and S.H. Chung (1974) The evolution of the retinotectal may during development in Xenopus. Proc. R. Lond. Soc. [Biol.] 185:301 330

Holland, R.L., T.J. Horder, and A.J. Pilgrim (1981) The size and shape of goldfish optic nerve fibre arborisations in normal tecta and early in regeneration of optic nerve. J. Physiol. (Lond.) 317:77-78P.

Jacobson, M., and R.M. Gaze (1964) Types of visual response from single units in the optic tectum and optic nerve of the goldfish. Q. J. Exp. Physiol. XLIX:199-209.

Jacobson, M, and R.M. Gaze (1965) Selection of appropriate tectal connections by regenerating optic fibers in adult goldfish. Exp. Neurol. 13:418430 .

Johns, P.R., and S.S. Faster (1977) Growth of the adult goldfish eye. Increase in retinal cell number. J. Comp. Neurol. 176:331-342.

Landreth, G.E.. E.A. Neale, J.H. Neale, R.S. Ruff, M.R. Braford, Jr., R.G. Northeutt, and B.W. Agranoff (1975) Evaluation of (3H)proline for auto radiographic tracing of axonal projections in the teleost visual system Brain Res. 91:25-42

LaVail, J.H., and M.D. LaVail (1974) The retrograde intraxonal transport of HRP in the chick visual system: A light and electron microscopic study. J. Comp. Neurol 157:303-358.

Leghissa, S. (1955) I a struttura microscopica e la citoarchitettura del tetto ottico dei pesci teleostei. Z. Anat. Entwickl. Gesch. 118:427-463.

Meyer, R.L. (1977) Hye-in-water electrophysiological mapping of goldfish with and without tectal lesions. Exp. Neurol. 56:23-41.
Meyer, R.L. (1978) Evidence from thymidine labeling for continuing growth of retina and tectum in juvenile goldfish. Exp. Neurol. 59:99-111.

Meyer, R.L. (1980) Mapping the normal and regenerating retinotectal projection of goldfish with autorudiographic methods. J. Comp. Neurol. 189:273-289

Potter, H.D. (1972) Terminal arborizations of retinotectal axons in the bull frog. J. Comp. Neurol, 144:269-284

Ramón y Cajal, S. (1952) Histologie du Système Nerveux de l'Homme et des Vertébrés. Madrid: CSJC.

Raymond, P.A., and S.S. Easter, Jr. (1983) Postembryonic growth of the optic tectum in goldfish. I. Location of germinal cells and number of neurons produced. J. Neurosci. 3:1077-1091.

Romeskie, M., and S.C. Sharma (1979) The goldfish optic tectum: A Golgi study. Neuroscience 4:625-642.

Rusoff, A.C. (1984)Paths of axons in the visual system of perciform fish and implications of these paths for rules governing axonal growth. J. Neurosci. $4: 1414-1428$

Rusoff, A.C., and S.S. Easter (1980) Order in the optic nerve of goldfish. Science 208:311-312.

Schmidt, J.T. (1979) The laminar organization of optic nerve fibers in the tectum of goldfish. Proc. R. Soc. Lond. Biol. 205:287-306.

Schmidt, J.T., C.M. Cicerone, and S.S. Easter (1978) Expansion of the half retinal projection to the tectum in goldfish. An electrophysiological and anatomical study. J. Comp. Neurol. 177:257-277.

Sharma, S.C. (1972) The retinal projections in the goldfish: and experimen tal study. Brain Res. 39:213-223.

Springer, A.D., and J.G. Gaffney (1981) Retinal projections in the goldfish: A study using cobaltous lysine. J. Comp. Neurol. 203:401-424.

Stuermer, C.A.O. (1978) The retino-tectale Projektion beim Goldfisch (Car assius auratus). Eine Unterschung zur Spezifität neuraler Verbindungen. Doctoral Dissertation, University of Freiburg.

Stuermer, C.A.O. (1983) Morphology of retinal axonal terminal arbors in the goldfish tectum. Neurosci. Abstr. 9:59.

Stuermer, C.A.O., and S.S. Easter, Jr. (1982) Growth related order of optic axons in the goldfish tectum. Neurosci. Abstr. 8:451.

Stuermer, C.A.O., and S.S. Easter, Jr. (1983) A comparison of the normal and regenerated retinotectal pathways of goldfish. J. Comp. Neurol. 223:57-76

Stuermer, C.A.O., and S.S. Easter, Jr. (1984a) Goldfish retinal axons: Intratectal pathways to their sites of termination. Invest. Ophthalmol. Vis Sci. [SuppI.]24:8.

Stuermer, C.A.O., and S.S. Easter, Jr. (1984b) Rules of order in the retinotectal fascicles of goldfish. J. Neurosci. 4:1045-1051.

Vanégas, H., and S.O.E. Ebbesson (1973) Retinal projections in the perchlike teleost Engerres plumieri. J. Comp. Neurol. 151:331-358. 